\title{
Southern Ocean carbon-wind stress feedback
}

\author{
Ben Bronselaer ${ }^{1} \cdot$ Laure Zanna $^{1}$ (D) David R. Munday ${ }^{2} \cdot$ Jason Lowe ${ }^{3}$
}

Received: 19 March 2017 / Accepted: 8 December 2017 / Published online: 7 February 2018

(c) The Author(s) 2017. This article is an open access publication

\begin{abstract}
The Southern Ocean is the largest sink of anthropogenic carbon in the present-day climate. Here, Southern Ocean $p \mathrm{CO}_{2}$ and its dependence on wind forcing are investigated using an equilibrium mixed layer carbon budget. This budget is used to derive an expression for Southern Ocean $p \mathrm{CO}_{2}$ sensitivity to wind stress. Southern Ocean $p \mathrm{CO}_{2}$ is found to vary as the square root of area-mean wind stress, arising from the dominance of vertical mixing over other processes such as lateral Ekman transport. The expression for plhbox $\{\mathrm{CO}\}_{-}\{2\}$ is validated using idealised coarse-resolution ocean numerical experiments. Additionally, we show that increased (decreased) stratification through surface warming reduces (increases) the sensitivity of the Southern Ocean $p \mathrm{CO}_{2}$ to wind stress. The scaling is then used to estimate the wind-stress induced changes of atmospheric $p \mathrm{CO}_{2}$ in CMIP5 models using only a handful of parameters. The scaling is further used to model the anthropogenic carbon sink, showing a long-term reversal of the Southern Ocean sink for large wind stress strength.
\end{abstract}

Keywords Southern Ocean · Carbon cycle $\cdot$ Climate feedback $\cdot$ Wind stress · Air-sea carbon fluxes.

\section{Introduction}

Westerly winds over the Southern Ocean and their impact on the atmosphere-ocean heat and carbon exchange have been of great scientific interest in recent years (e.g., Lauderdale et al. 2013; Lenton et al. 2013). Southern Hemisphere westerly wind strength has been observed to increase over the last few decades (Swart et al. 2014) and coupled climate models project a further rise over the next century (Bracegirdle et al. 2013). Winds over the Southern Ocean lead to northwards advection of water via Ekman transport, causing upwelling

Ben Bronselaer

benjamin.bronselaer@noaa.gov

Laure Zanna

laure.zanna@physics.ox.ac.uk

David R. Munday

danday@bas.ac.uk

Jason Lowe

jason.lowe@metoffice.gov.uk

1 Atmospheric, Oceanic and Planetary Physics, Department of Physics, University of Oxford, Oxford OX1 3PU, UK

2 British Antarctic Survey, Madingley Road, Cambridge CB3 OET, UK

3 Met Office Hadley Centre, FitzRoy Road, Exeter, Devon EX1 3PB, UK of deep ocean waters and driving an overturning circulation. The winds ventilate the deep ocean and expose its carbon content to the atmosphere. The strengthened ventilation as winds increase is thought to increase the transfer of carbon from the ocean into the atmosphere (Sarmiento et al. 1998; Lauderdale et al. 2017) and increase global mean temperature through an enhanced greenhouse effect.

These wind-induced changes in atmospheric $\mathrm{CO}_{2}$ levels are generally driven by large changes in pre-formed (or abiotic) and regenerated (or biological) ocean carbon reservoirs (Broecker 1974), that nearly but not exactly compensate each other (Lauderdale et al. 2013; Munday et al. 2014). Consideration of pre-formed and regenerated carbon reservoirs have proven fruitful in understanding how ocean circulation impacts atmospheric $\mathrm{pCO}_{2}$. This is because when the total atmosphere and ocean inventory of carbon is fixed, knowledge of the ocean carbon inventories equates to knowledge of atmospheric $\mathrm{pCO}_{2}$ (see, e.g., Goodwin et al. 2007, 2008). In an abiotic ocean, it is sufficient to predict the pycnocline depth in order to understand the atmospheric carbon dioxide concentration for both wind and vertical mixing changes (Ito and Follows 2003). The inclusion of biology, and the additional carbon reservoirs this gives rise to, breaks this strong connection and the details of how the ocean is ventilated and how the overturning circulation varies also become important (Toggweiler et al. 2003; Munday et al. 2014). This can be 
summarised in terms of what fraction of the ocean is filled by water from different end members, such as the Southern Ocean or North Atlantic, and their relative carbon content (Marinov et al. 2008a, b). In all cases, the carbon is exchanged through an air-sea flux across the air-sea interface. Different regions can acts as net sources or sinks of carbon.

The Southern Ocean is currently the largest sink of oceanic anthropogenic carbon (Khatiwala et al. 2009). Quere et al. (2007) find a reduction in the Southern Ocean sink of atmospheric carbon of $0.08 \mathrm{PgCyr}^{-1}$ per decade, between 1981 and 2004, using atmospheric $\mathrm{CO}_{2}$ observations and atmospheric inversions. They attribute the reduction in the sink to the observed increase in westerly winds. However, natural variability can strongly affect present and future estimates of changes in the Southern Ocean carbon sink, as illustrated in Fay and McKinley (2013), Majkut et al. (2014), Landschutzer et al. (2015), and McKinley et al. (2016).

We therefore often rely on numerical simulations to study past, current and future trends in Southern Ocean carbon fluxes. Studies such as Lovenduski and Ito (2009) use models to analyse the Southern Ocean carbon sink in a changing climate and predict a reduction of the carbon sink in the coming century. Similarly, Ito et al. (2015) employ sensitivity experiments to demonstrate that under climate change, elevated westerly winds not only increase outgassing of natural carbon, but also increase the ocean uptake of anthropogenic carbon. Ito et al. (2015) also show that increases in freshwater fluxes lead to increased storage of biological carbon at the expense of atmospheric $\mathrm{CO}_{2}$, the net result being a strengthening of the overall carbon sink in the future.

Past research shows that the lack of continuous observations and the transient response of the carbon cycle to simultaneously varying forcings (i.e. wind stress and buoyancy fluxes) limits the accuracy of observed and projected Southern Ocean carbon sink estimates. Projecting the exact influence of wind stress from other forcings on the natural and anthropogenic Southern Ocean air-sea carbon flux in coupled climate simulations and observations remains a challenge. In addition, the constraint of total carbon inventory being constant is violated in anthropogenic climate change scenarios, where emissions add to the total inventory. In this case, it could be difficult to predict how atmospheric $\mathrm{pCO}_{2}$ may vary, since knowledge of multiple ocean carbon inventories (Ito and Follows 2005), which are all large, is required.

An alternative approach, which we use here, is to exploit the dominance of the Southern Ocean with regards to air-sea carbon fluxes. Lauderdale et al. (2016) show that the air-sea carbon disequilibrium due to wind-induced Southern Ocean circulation has the strongest influence on the air-sea carbon flux compared to other forcings. Since air-sea carbon exchange is regulated by the local difference in partial pressure (Wanninkhof 1992), it becomes natural to consider whether prediction of the Southern Ocean partial pressure of $\mathrm{CO}_{2}$ could be a useful way to quantitatively predict the atmospheric carbon dioxide concentration. This approach complements that of ocean carbon reservoirs, since changes in the air-sea exchange must ultimately reflect changes in ocean carbon reservoirs, and vice versa. Understanding how the wind stress will influence the Southern Ocean $\mathrm{pCO}_{2}$ and carbon flux in the future is therefore key to understanding the overall evolution of the carbon flux.

In this paper, our aim is to derive an expression for calculating the change in Southern Ocean and atmospheric $p \mathrm{CO}_{2}$ due to changing Southern Ocean winds. The expression allows us to isolate the impact of Southern Ocean winds on the ocean and atmospheric carbon levels from the various other forcings and feedbacks in the coupled climate system. The paper is organised as follows. We describe an idealized configuration of an ocean general circulation model used to verify our theory in Sect. 2. We then present the derivation of a set of diagnostic relationships linking Southern Ocean and atmospheric $\mathrm{CO}_{2}$ concentrations to Southern Ocean areamean wind stress, and employ model simulations to test the validity of these relationships under various wind stress scenarios in Sect. 3. We further explore the sensitivity of natural Southern Ocean carbon to wind stress in response to climate change-induced stratification changes in CMIP5 models and examine the Southern Ocean anthropogenic carbon sink as a function of wind stress in Sect. 4. We conclude in Sect. 5.

\section{MITgcm model description}

To explore the response of Southern Ocean $\mathrm{CO}_{2}$ to wind forcing and verify theoretical predictions described in Sect. 3, we employ the MITgcm (Marshall et al. 1997) in an idealised set-up designed to represent the Atlantic and Southern Oceans. The set-up is similar to Munday et al. (2014) at $2^{\circ} \times 2^{\circ}$ horizontal grid spacing with eddies parametrized using the Gent-McWilliams scheme with a constant coefficient. The domain (shown schematically in Fig. 1a) is a sector $20^{\circ}$-wide in longitude, extending to $60^{\circ} \mathrm{N} / \mathrm{S}$ with a re-entrant channel between $60^{\circ} \mathrm{S}$ and $40^{\circ} \mathrm{S}$ to allow for a circumpolar current. The basin is $5000 \mathrm{~m}$ deep, except at the channel boundaries where a $2500 \mathrm{~m}$ deep sill represents Drake Passage. The model size and resolution are chosen such that a large set of numerical experiments (different amplitude of wind forcing and different eddy diffusion coefficients), can be run for centuries while capturing the features of a large-scale circulation at low computational expense. The ocean model contains a biogeochemical component with five active tracers underlying a well-mixed atmospheric box which solves for atmospheric partial pressure of $\mathrm{CO}_{2}, p \mathrm{CO}_{2}$ (Follows et al. 2006). Such a setup is widely used to conduct large-scale ocean studies (e.g., Wolfe and Cessi 2010; Ito and Follows 2003; Munday et al. 2013). 
A
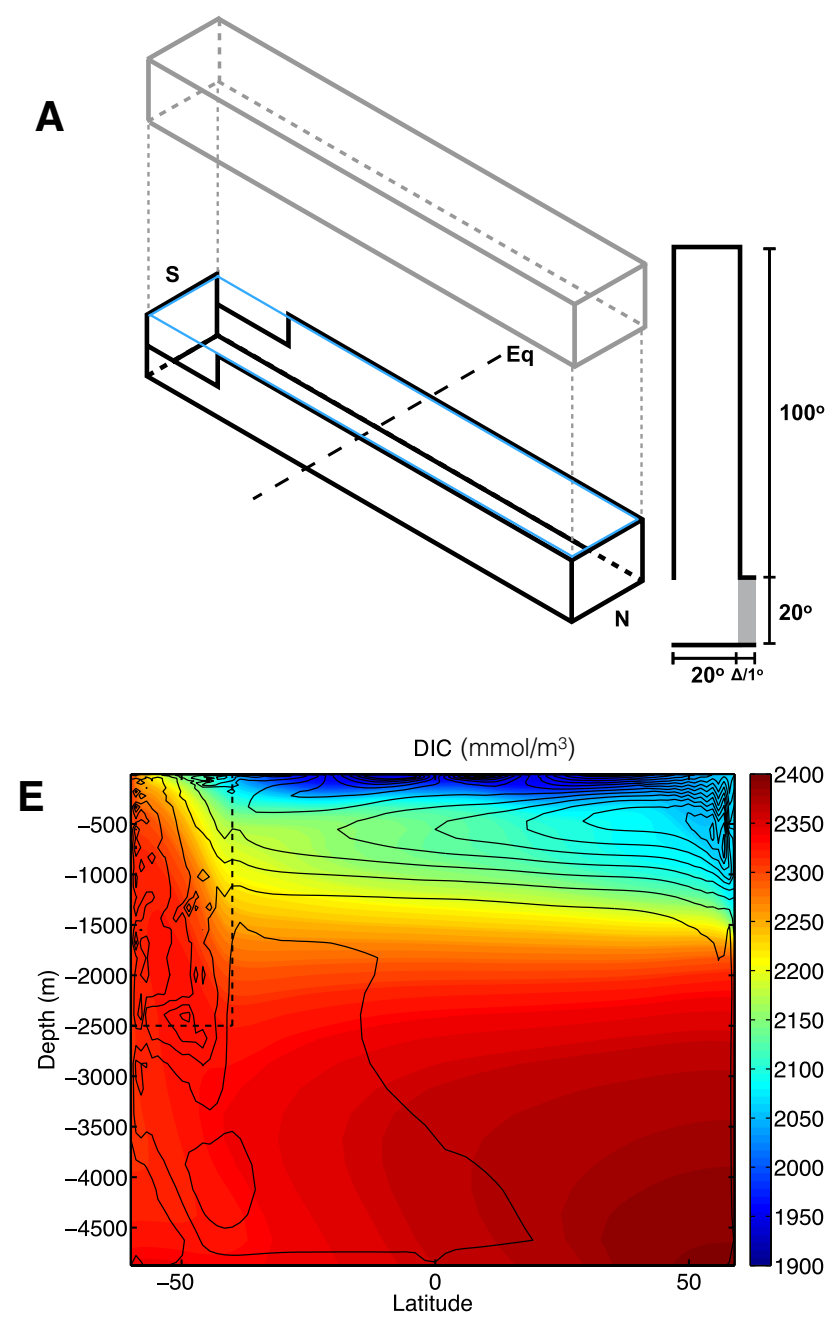

Fig. 1 a Schematic of MITgcm sector. Latitudinal profiles for the control simulations of: b wind forcing $\left(\mathrm{N} / \mathrm{m}^{2}\right)$, with the dashed line showing a $2 \times \overline{\tau_{S O}}$ perturbation; c 30 -day temperature restoring $\left({ }^{\circ} \mathrm{C}\right)$ and d 10-day salinity restoring (psu). e Zonally averaged Dissolved

The ocean is forced with a zonal wind stress profile $\tau$ (Fig. 1b) chosen to induce an idealised ocean circulation. The wind stress forcing over the Southern Ocean is set to $\overline{\tau_{S O}}=0.13 \mathrm{~N} / \mathrm{m}^{2}$, where the subscript "SO" refers to the Southern Ocean between $60^{\circ}$ and $40^{\circ} \mathrm{S}$ and the overbar indicates an area mean. Radiative and freshwater fluxes are prescribed through temperature and salinity restoring profiles (Fig. 1c, d), which broadly match the observed distributions in the Atlantic. The model parameters are as in Munday et al. (2014). The same model was used in Bronselaer et al. (2016) to demonstrate the effect of Southern Ocean winds on the North Atlantic air-sea carbon flux.

The steady-state distribution of Dissolved Inorganic Carbon, DIC, is shown in Fig. 1e. The pattern and magnitude of DIC is reminiscent of other modelling studies (Ito and Follows 2005) and observations (Gruber 1998), with a large
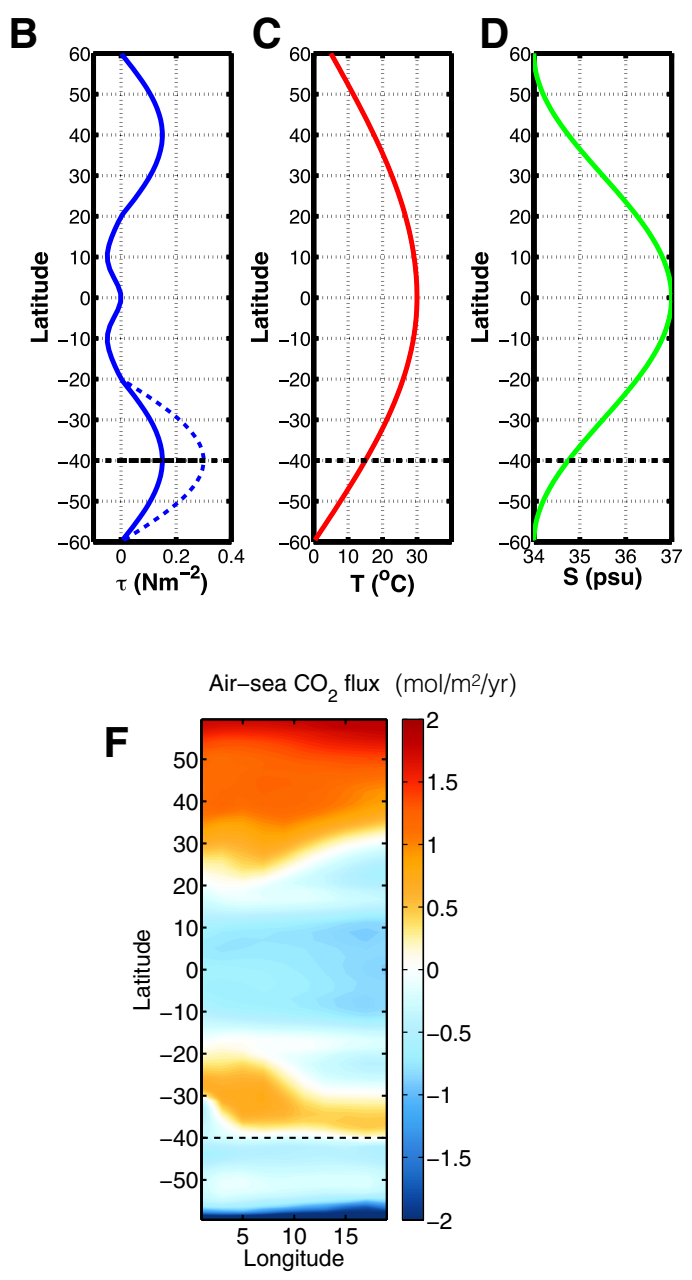

Inorganic Carbon, DIC $\left(\mathrm{mmol} / \mathrm{m}^{3}\right)$. The thin black lines are residual overturning stream function contours spaced $1 \mathrm{~Sv}$ apart. f Air-sea carbon flux (mol/ $/ \mathrm{m}^{2} /$ year), $F_{\text {air-sea }}$. Dashed black lines in b-f indicate the extent of the channel

carbon reservoir in the deep ocean. The pattern and magnitude of the air-sea $\mathrm{CO}_{2}$ flux (Fig. 1f) agrees well with observations (Takahashi et al. 2009), with a uniform control atmospheric $p \mathrm{CO}_{2}$ value of $300 \mathrm{ppm}$. There is outgassing of carbon in the Southern Ocean and ocean uptake to the north, in the extension of the sub-tropical gyre boundary currents, in both the model and in observations.

To simulate an increase in Southern Ocean winds, we multiply the wind stress between $60^{\circ} \mathrm{S}$ and $20^{\circ} \mathrm{S}$ by a constant (see Fig.1b). Seven experiments are run, from a 10 to a 300\% increase in Southern Ocean wind stress amplitude. Each experiment is run for 400 years, after which time the upper $1000 \mathrm{~m}$ in the Southern channel has fully equilibrated. The timescale associated with vertical mixing is such that upper ocean $p \mathrm{CO}_{2}$ in the Southern Ocean equilibrates within 60 years for all magnitudes of wind perturbation. Figure $2 \mathrm{a}$ 
shows that the response of the Southern Ocean circulation to local changes in wind forcing is linear, as illustrated by the Ekman transport at the northern edge of the channel vs. $\overline{\tau_{S O}}$. However, the local mixed layer depth varies non-linearly (Fig. 2b). The increase in Ekman transport due to increased wind forcing acts to decrease the Southern Ocean $\underline{p \mathrm{CO}_{2}^{o}}$, $\overline{p \mathrm{CO}_{2}^{o}}$, while a deepening mixed layer acts to increase $\overline{p \mathrm{CO}_{2}^{o}}$.

The patterns of the surface response to wind forcing are shown in Fig. $2 \mathrm{c}$, d using the $2 \times \overline{\tau_{S O}}$ experiment. The increased upwelling of cold and deep water in the channel leads to local surface cooling (Fig. 2c). The southern hemisphere $p \mathrm{CO}_{2}^{o}$ (Fig. 2d) increases due to enhanced upwelling of carbon.

\section{A diagnostic equation for Southern Ocean carbon}

\subsection{Southern Ocean carbon mixed-layer budget}

The oceanic concentration of carbon, DIC, obeys the following equation in general circulation models:

$\frac{\partial D I C}{\partial t}=-\nabla \times(\mathbf{u} D I C)+\nabla \times(\mathbf{D} \times \nabla D I C)+\frac{\partial F_{\text {air }- \text { sea }}}{\partial z}+S_{\text {bio }}$, where $\nabla$ is the $3 \mathrm{D}$ vector differential operator, $\mathbf{u}=(u, v, w)$ is the residual 3D velocity field, given by the sum of the Eulerian $\mathbf{u}^{E k}$ and eddy $\mathbf{u}^{*}$ velocities (Marshall and Radko 2003), D is the diffusivity tensor, $F_{\text {air-sea }}$ is the air-sea carbon flux and $S_{b i o}$ is the biological source/sink of both soft tissue and calcium carbonate (Follows et al. 2006).

The interaction between the atmosphere and the ocean occurs within a shallow mixed layer, we therefore integrate Eq. 1 over the depth of the mixed layer $h$ and assume a vertically uniform DIC concentration within the mixed layer, $D I C_{h}$. The mixed layer carbon budget is obtained by keeping only the dominant terms in the integrated equation (Levy et al. 2013; Bronselaer 2016), leading to the balance:

$$
\begin{aligned}
h \frac{\partial D I C_{h}}{\partial t}= & -\Delta_{z} D I C\left(w_{h}+u \frac{\partial h}{\partial x}+v \frac{\partial h}{\partial y}\right) \\
& +F_{\text {air-sea }}+\left[S_{b i o}\right]_{h},
\end{aligned}
$$

where $w_{h}$ is the vertical velocity at the bottom of the mixed layer and is positive upward. If the mixed layer is shoaling, the $w_{h}$ is set to zero, since detrainment has no impact on the mixed layer DIC concentration. $\Delta_{z} D I C$ is the vertical difference in DIC between the mixed layer and the thermocline.
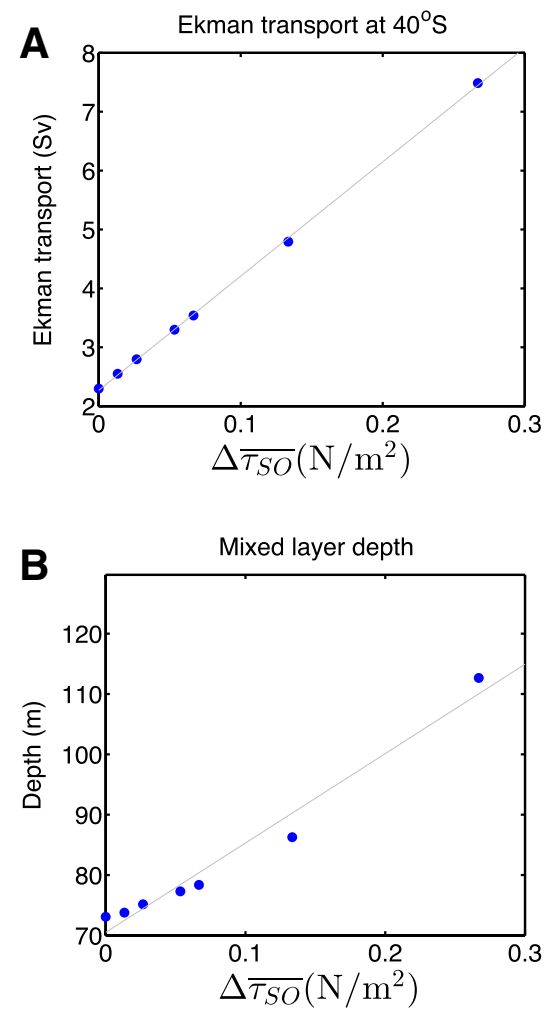

Fig. 2 a Northward Ekman transport at $40^{\circ} \mathrm{N}$ calculated as the Eulerian transport between 0 and $100 \mathrm{~m}$ depth and $\mathbf{b}$ mean mixed layer depth in the channel as a function of changes in Southern Ocean wind stress anomalies, $\Delta \overline{\tau_{S O}}$. c Sea Surface Temperature $\left({ }^{\circ} \mathrm{C}\right)$ and $\mathbf{d}$
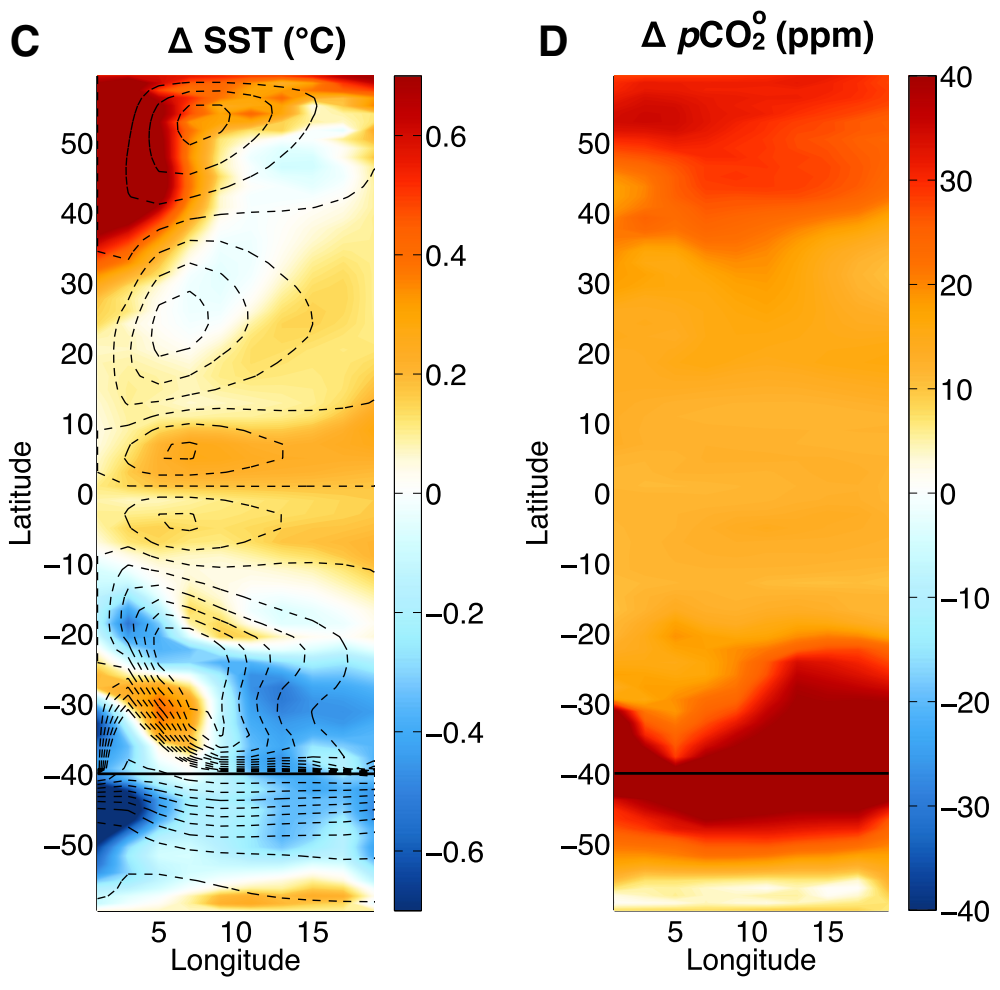

Surface ocean $p \mathrm{CO}_{2}(\mathrm{ppm})$ anomalies in the $2 \times \tau_{S O}$ experiment relative to the control experiment. Dashed lines in $\mathbf{c}$ show the barotropic stream function in the $2 \times \overline{\tau_{S O}}$ experiment, and the solid lines indicate the extent of the channel 
$\Delta_{z} D I C$ is negative, since DIC values in the thermocline are greater than in the mixed layer. $[\ldots]_{h}$ indicates an integral over the mixed layer.

The mixed layer carbon equation in Eq. 2 incorporates the mixed layer carbon fluxes similarly to Levy et al. (2013), but also includes upwelling from below the thermocline, as in Ito et al. (2004) and Follows and Williams (2004). The dominant carbon fluxes in and out of the mixed layer expressed in Eq. 2 are schematically shown in Fig. 3 and comprises of vertical and horizontal advection, air-sea flux and biological flux. Vertical advection, $\Delta_{z} D I C w_{h}$, contains contributions from the large scale Ekman divergence and from local turbulent entrainment. Horizontal advection, $\Delta_{z} D I C\left(u \frac{\partial h}{\partial x}+v \frac{\partial h}{\partial y}\right)$, can pump or remove carbon when lateral induction across the sloping mixed layer boundary is occuring. The air-sea flux of carbon, $F_{\text {air-sea }}$, exchanges carbon between the ocean and the atmosphere, while the biological flux, $\left[S_{b i o}\right]_{h}$, removes carbon from the mixed layer and transfers it to the deep ocean.

\subsection{Prediction of equilibrium oceanic $p \mathrm{CO}_{2}$}

Wind stress-induced changes in sources and sinks of carbon within the mixed layer have the potential to affect the DIC concentration within the mixed layer and the oceanic partial pressure of carbon. The terms $w_{h}, v$ and $F_{\text {air-sea }}$ in Eq. 2 can be expressed in terms of the wind stress $\tau$. The vertical velocity at the bottom of the mixed layer is estimated through kinetic energy balance (Niiler and Kraus 1977):

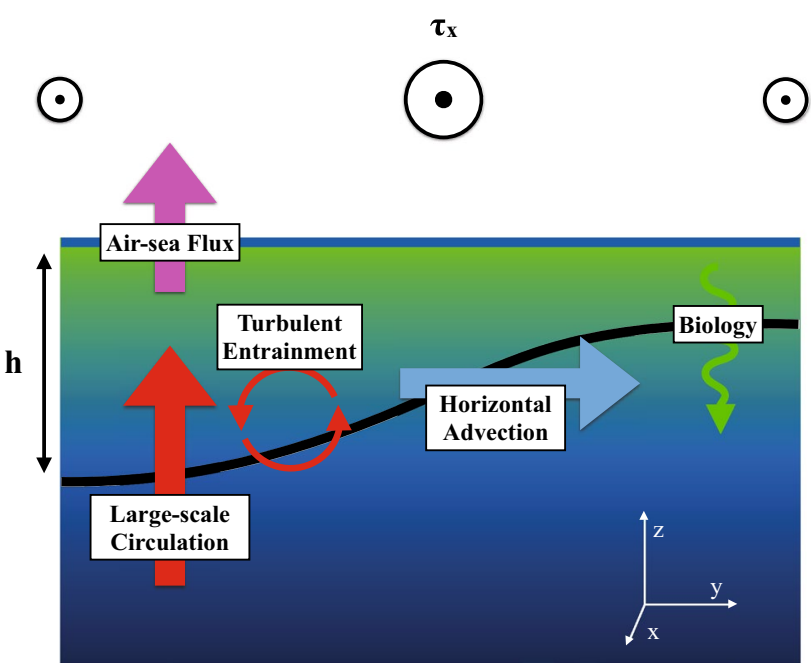

Fig. 3 Diagram of the dominant carbon fluxes in and out of the Southern Ocean mixed layer with depth $h$ : vertical advection (red arrows), with a contribution due the large scale Ekman divergence and local turbulent entrainment; horizontal advection (blue) when there is horizontal transport of carbon across the sloping mixed layer boundary; the air-sea flux of carbon (magenta) and biological flux (green). The zonal wind stress is shown at the top of the figure $w_{h}=\frac{2}{\alpha g h \Delta_{z} T}\left(m_{0} u_{*}^{3}-\alpha g \frac{h Q}{2 \rho_{0} c_{p}}\right)$,

where $\alpha$ is the thermal expansion coefficient, $g$ is the gravitational acceleration, $m_{0}$ is a constant (Davis et al. 1981) and $c_{p}$ is the specific heat capacity. $Q$ is the surface net radiative heat flux and $\Delta_{z} T$ is the vertical temperature difference between the mixed layer and the thermocline. The terms $Q$ and $\Delta_{z} T$ are assumed to be constant for each wind-perturbation experiment, with no explicit dependence on the wind-stress. The frictional wind speed is given by $u_{*}=\left|\tau / \rho_{0}\right|^{1 / 2}$. This expression for $w_{h}$ is chosen because it contains contributions from both the large scale circulation, via $\Delta_{z} T$, and from local turbulent entrainment, via windinduced mixing and buoyancy forcing. The implications of expressing $w_{h}$ in terms of the large scale Ekman divergence, rather than through a kinetic energy balance will be addressed in Sect. 3.4. The meridional Eulerian velocity in the mixed layer can be estimated using the Ekman velocity $v^{E k}=\tau /\left(f \rho_{0} h\right)$, where $\rho_{0}$ is a reference density and $f$ is the Coriolis parameter. The meridional eddy velocity $v^{*}$ partially compensates the Eulerian component $v^{E k}$ and depends on the isopycnal slope (Gent and McWilliams 1990). Since the slope of isopycnals in the Southern Ocean channel varies linearly with wind stress in our sensitivity experiments, we set $v^{*}$ to be proportional to $v^{E k}$ such that $v^{*}=-e_{G M} v^{E k}$, where $0<e_{G M}<1$, and $v=v^{E k}+v^{*}=\left(1-e_{G M}\right) v^{E k}$.

The Southern Ocean air-sea carbon flux is approximated by the parametrization of Wanninkhof (1992) used in most complex climate models, including those in CMIP5 and is given by:

$F_{\text {air-sea }}=K \tau\left(p \mathrm{CO}_{2}^{a}-p \mathrm{CO}_{2}^{o}\right)$,

where the wind stress $\tau$ is proportional to the square of the wind speed. $K$ measures the turbulent air-sea gas transfer and solubility such that $K \tau=k$, where $k$ is the piston velocity of Wanninkhof (1992) which varies as the square of the surface wind speed. $p \mathrm{CO}_{2}^{a}$ and $p \mathrm{CO}_{2}^{o}$ are the atmospheric and oceanic partial pressure of $\mathrm{CO}_{2}$, respectively.

The expressions for $w_{h}, v$ and $F_{\text {air-sea }}$ can be substituted into Eq. 2 to solve for $p \mathrm{CO}_{2}^{o}$ at equilibrium when $\frac{\partial D I C_{h}}{\partial t}=0$ :

$$
\begin{aligned}
p \mathrm{CO}_{2}^{o}= & -\frac{\Delta_{z} D I C}{K}\left(\frac{2 m_{0}}{\alpha g h \Delta_{z} T \rho_{0}^{3 / 2}} \tau^{1 / 2}\right. \\
& \left.+\frac{Q}{\tau \rho_{0} C_{p}}+\frac{\left(1-e_{G M}\right)}{\rho_{0} f h} \frac{\partial h}{\partial y}+\frac{u}{\tau} \frac{\partial h}{\partial x}\right) \\
& +\frac{\left[S_{b i o}\right]_{h}}{K \tau}+p \mathrm{CO}_{2}^{a} .
\end{aligned}
$$


We are interested in the area-average change in $p \mathrm{CO}_{2}^{o}$ so we take a weighted average of Eq. 5 across the Southern Channel. The averaged equation is given as:

$$
\begin{aligned}
\overline{p \mathrm{CO}_{2}^{o}}= & -\overline{\left(\frac{\Delta_{z} D I C}{K h}\right) \frac{2 m_{0}}{\alpha g \Delta_{z} T \rho_{0}^{3 / 2}} \tau_{S O}^{1 / 2}} \\
& +\overline{\left(\frac{\Delta_{z} D I C}{K}\right) \frac{Q}{\Delta_{z} T \rho_{0} C_{p} \tau_{S O}}} \\
& -\overline{\left(\frac{\Delta_{z} D I C}{K h}\right) \frac{\left(1-e_{G M}\right)}{\rho_{0} f} \frac{\partial h}{\partial y}} \\
& +\frac{\left[S_{b i o}\right]_{h}}{K \tau_{S O}}+p \mathrm{CO}_{2}^{a} .
\end{aligned}
$$

The overbar indicates an area mean over the Southern Ocean as defined in the previous section. Because the channel is zonally periodic, the averaged zonal advection $\frac{u}{\tau} \frac{\partial h}{\partial x}$ is zero.
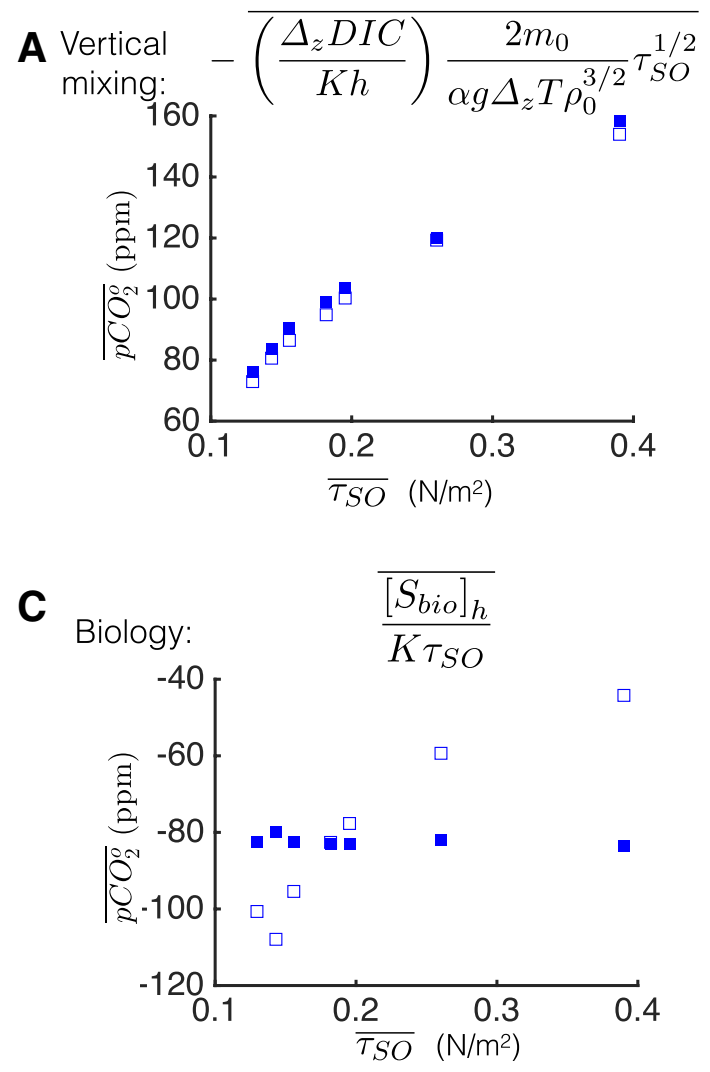

Fig. 4 Contributions of a vertical mixing, b meridional advection, $\mathbf{c}$ biology and $\mathbf{d}$ radiative flux terms to the estimate of Southern Ocean $p \mathrm{CO}_{2}$ (Eq. 6) as a function of Southern Ocean wind stress, $\overline{\tau_{S O}}$. Filled squares show the terms as they appear in Eq. 6 and the empty squares show the terms with the average split to isolate $\overline{\tau_{S O}}$. b Shows
Figure 4 shows the magnitude of the terms in Eq. 6 (filled squares) as a function of area-mean wind stress $\overline{\tau_{S O}}$ for the vertical mixing (panel a), meridional transport (panel b), biological flux (panel c) and radiative flux (panel d). The area-weighted Southern Ocean $p \mathrm{CO}_{2}^{o}$ is dominated by vertical mixing, while biology acts as a negative feedback. Meridional advection due to Ekman transport is second order compared to vertical mixing, and radiative flux term (diagnosed from each perturbation experiment where $Q$ varies) is negligible.

The ultimate goal is to derive an equation expressing the sensitivity of mean ocean $p \mathrm{CO}_{2}$ as a function of mean wind stress, i.e. $\overline{p \mathrm{CO}_{2}^{o}}\left(\overline{\tau_{S O}}\right)$. We would therefore like to split the area integral of the different terms to isolate $\overline{\tau_{S O}}$ : e.g.

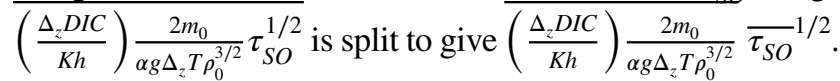

Figure 4 also shows the magnitude of the terms in Eq. 6 as a function of area-mean wind stress $\overline{\tau_{S O}}$, with the area integral split (empty squares) to isolate $\overline{\tau_{S O}}$ for the vertical mixing (panel a), biological flux (panel c) and radiative flux (panel d).
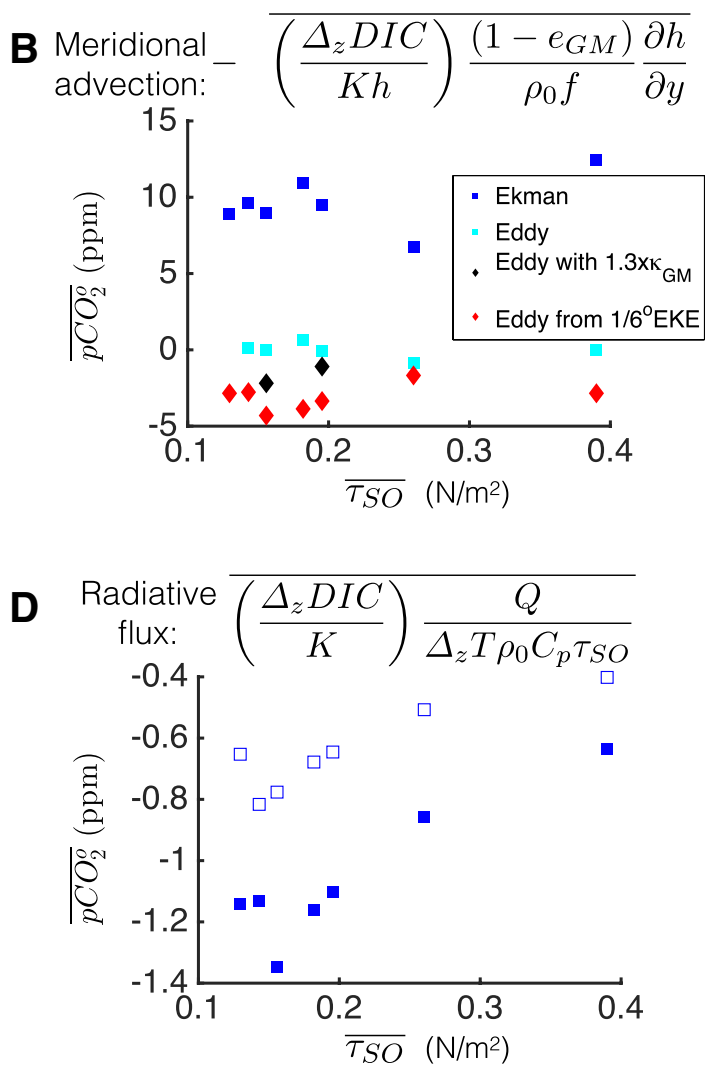

the Ekman (dark blue) and eddy (cyan) contributions, as well as the eddy contributions in experiments with the GM coefficient increased by $30 \%$ (black) and with meridional eddy velocities estimated from eddy-permitting Southern Ocean wind stress experiments performed by Munday et al. (2013). Control atmospheric $p \mathrm{CO}_{2}$ is $300 \mathrm{ppm}$ 
Figure 4 shows that splitting the area integrals results in large errors for all terms (due to large spatial correlations between the wind stress and other variables in these components), except for the vertical mixing term which leads only to $5 \%$-error. We therefore only use the split integral for the vertical mixing term.

The biology term $\frac{\overline{\left[S_{\text {bio }}\right]_{h}}}{K \tau_{S O}}$ in Eq. 5 is shown in Fig. $4 c$ to be insensitive to changes in $\overline{\tau_{S O}}$. This suggests that $\left[S_{b i o}\right]_{h}$ is directly proportional to $\tau_{S O}$ despite having no explicit dependence on $\tau_{S O}$. As the wind stress increases, so does the biological carbon uptake which reduces ocean $p \mathrm{CO}_{2}$. The air-sea carbon flux increases linearly with wind stress, increasing the ocean $p \mathrm{CO}_{2}$ at the same rate. The net result is that ocean $p \mathrm{CO}_{2}$ is not strongly affected by changes in the biological carbon flux. However, this behaviour may vary between models. Note that entrainment can also supply nutrients to the surface water, therefore affecting biology. This can compensate the upwelling of DIC, acting as a negative feedback as shown in Follows and Williams (2004).

The effect of ocean eddies is parametrised as an isopycnal diffusion term with a constant diffusivity coefficient $\kappa_{G M}$ in the MITgcm set-up used in the present study. In principle, as the wind stress increases, $\kappa_{G M}$ should increase to model the increasing eddy activity and their response the changing isopycnal slope. However $\kappa_{G M}$ is constant in the MITgcm experiments. To address this concern, we run simulations whereby $\kappa_{G M}$ is increased by $30 \%$ and the strength of the eddy-induced meridional advection term in Eq. 5 diagnosed, shown in black in Fig. 4b. Additionally, Munday et al. (2013) performed eddy-permitting $\left(1 / 6^{\circ}\right.$ horizontal resolution) Southern Ocean wind-stress perturbation experiments in a similar MITgcm configuration as used in this paper. They found that the basinaveraged Eddy Kinetic Energy (EKE) is linearly dependent on the maximum Southern Ocean wind stress. We therefore use the diagnosed EKE from the Munday et al. (2013) experiments to estimate the meridional eddy velocity and subsequently the eddy-induced meridional advection term in Eq. 5, shown in red in Fig. 4b. In each case, the net contribution of eddies towards Southern Ocean $p \mathrm{CO}_{2}$ is small, less than $5 \mathrm{ppm}$ for wind stress values of up to $\overline{\tau_{S O}}=0.4 \mathrm{~N} / \mathrm{m}^{-2}$; and always less than $20 \%$ of the Ekman contribution.

The scaling for the sensitivity of Southern Ocean $p \mathrm{CO}_{2}$ to wind stress can therefore be written as

$$
\begin{aligned}
\overline{p \mathrm{CO}_{2}^{o}}\left(\overline{\tau_{S O}}\right)= & -\frac{\overline{\Delta_{z} D I C}}{h} \frac{2 m_{0}}{K \alpha g \Delta_{z} T \rho_{0}^{3 / 2}} \bar{\tau}_{S O}^{1 / 2} \\
& +p \mathrm{CO}_{2}^{a}+G_{1} .
\end{aligned}
$$

The term $G_{1}$ includes the contributions of terms which do not significantly vary with changes in Southern Ocean wind stress $\tau_{S O}$ or have a small contribution to the ocean $p \mathrm{CO}_{2}^{o}$ such as effects from Ekman, eddies, radiative flux and mixed layer biology. The term $G_{1}$ is given by:

$$
\begin{aligned}
G_{1}= & \overline{\left(\frac{\Delta_{z} D I C}{K}\right) \frac{Q}{\Delta_{z} T \rho_{0} C_{p} \tau_{S O}}} \\
& -\frac{\left(\frac{\Delta_{z} D I C}{K h}\right) \frac{\left(1-e_{G M}\right)}{\rho_{0} f} \frac{\partial h}{\partial y}}{\left[F_{b i o}\right]_{h}} \\
& +\frac{K \tau_{S O}}{}
\end{aligned}
$$

Equation 7 predicts that the equilibrium Southern Ocean partial pressure of $\mathrm{CO}_{2}$ varies as the square root of the mean Southern Ocean wind stress. Note that equilibrium here reflects the multi-centennial quasi-steady state of the mixed layer, and not the long-term millenial adjustment of the deep ocean. The relationship highlights the importance of vertical mixing and the air-sea flux over other factors, such as horizontal Ekman transport. The magnitude of the response of $\overline{p \mathrm{CO}_{2}^{o}}$ to $\overline{\tau_{S O}}$ is set by the quantities $\Delta_{z} D I C, h$ and $\Delta_{z} T$ in the Southern Ocean, while the contributions of horizontal Ekman transport, radiative forcing and biological productivity constitute a constant offset.

\subsection{Atmospheric $\mathrm{pCO}_{2}$ response}

In the absence of anthropogenic atmospheric carbon anomalies, an estimate of the equilibrium atmospheric $\mathrm{pCO}_{2}$ can be obtained by integrating the air-sea flux equation (Eq. 4) over the entire ocean surface and substituting for $\overline{p \mathrm{CO}_{2}^{o}}$ using Eq. 7, such that

$$
\begin{aligned}
p \mathrm{CO}_{2}^{a}= & \frac{P_{S O}}{1-P_{S O}} \frac{\overline{-\Delta_{z} D I C}}{h} \frac{2 m_{0}}{K \alpha g \Delta_{z} T \rho_{0}^{3 / 2}} \bar{\tau}_{S O}{ }^{1 / 2} \\
& +G_{2}\left(G_{1}, p \mathrm{CO}_{2 E}^{o}\right) .
\end{aligned}
$$

The area fraction of the Southern Ocean relative to the global ocean, weighted by the local wind stress is given by $P_{S O}=A_{S O} K \overline{\tau_{S O}}\left(A_{S O} K \overline{\tau_{S O}}+A_{E} K \overline{\tau_{E}}\right)^{-1}$, where $A$ is the area and the subscript " $S O$ " and " $E$ " indicate the Southern Ocean and rest of the global ocean, respectively. $p \mathrm{CO}_{2 E}^{o}$ is the ocean $p \mathrm{CO}_{2}$ outside of the Southern Ocean, which varies weakly with $\overline{\tau_{S O}}$ (not shown). All terms with weak or no dependence on $\overline{\tau_{S O}}$ are encapsulated in the term $G_{2}$ (see Appendix for further details). The fraction $\frac{P_{S O}}{1-P_{S O}}$ reflects changes in air-sea flux due to the gas constant sensitivity to wind, assuming constant ocean $\mathrm{CO}_{2}$ concentrations. The behaviour of $\frac{P_{S O}}{1-P_{S O}}$ 
depends on the local surface area and wind stress but the sensitivity of atmospheric $p \mathrm{CO}_{2}$ to Southern Ocean wind stress, similarly to the Southern Ocean $p \mathrm{CO}_{2}$, is primarily driven by the following Southern Ocean properties: $\Delta_{z} D I C$, $h$ and $\Delta_{z} T$.

\subsection{Verification of the Southern Ocean carbon equations}

Using MITgcm numerical simulations described in Sect. 2, we can verify the accuracy of the predictions of oceanic (Eq. 7) and atmospheric $p \mathrm{CO}_{2}$ (Eq. 9). The parameters used for the scaling are listed in Table 1. Because the DIC concentration at the Southern Ocean surface is determined by the DIC concentration of waters upwelled along isopycnals, $\Delta_{z} T$ is calculated with respect to the mean depth of the isopycnals outcropping in the Southern channel, taken at the northern edge of the channel $\left(40^{\circ} \mathrm{S}\right)$. In our set-up, this leads to an isopycnal depth of roughly $1000 \mathrm{~m}$ at $40^{\circ} \mathrm{S}$. The value of $K$ is calculated as $K \overline{\tau_{S O}}=42 \mathrm{~cm} / \mathrm{h}$ in the control simulation. In our set-up, the pycnocline depth, the mixed layer depth and the Ekman transport vary linearly with the wind, and the only square-root dependence with wind stress is derived from the entrainment at the base of the mixed layer.

Figure 5 shows the modelled (squares) and predicted (line) responses of $\overline{p \mathrm{CO}_{2}^{o}}$ as a function of Southern Ocean wind stress $\overline{\tau_{S O}}$. The prediction of $\overline{p \mathrm{CO}_{2}^{o}}$, using Eq. 7 and control state values of $\Delta_{z} D I C, h$ and $\Delta_{z} T$, matches the model simulations within $2 \%$. Both the modelled and predicted Southern Ocean $p \mathrm{CO}_{2}^{o}$ exhibit a square-root relationship as a function of wind stress. This reinforces our assumption that the key driver in setting Southern Ocean $p \mathrm{CO}_{2}^{o}$ and its sensitivity is wind-induced entrainment at the base of the mixed layer, rather than other factors such as lateral Ekman transport (encapsulated within the term $G_{1}$ in Eq. 7).

Figure 6 shows that the square-root scaling in Eq. 7 for Southern Ocean $p \mathrm{CO}_{2}$ remains insensitive to the size of the model domain $\left(40^{\circ}\right.$-wide basin, magenta curve), and the shape of the wind stress profile over the Southern Ocean

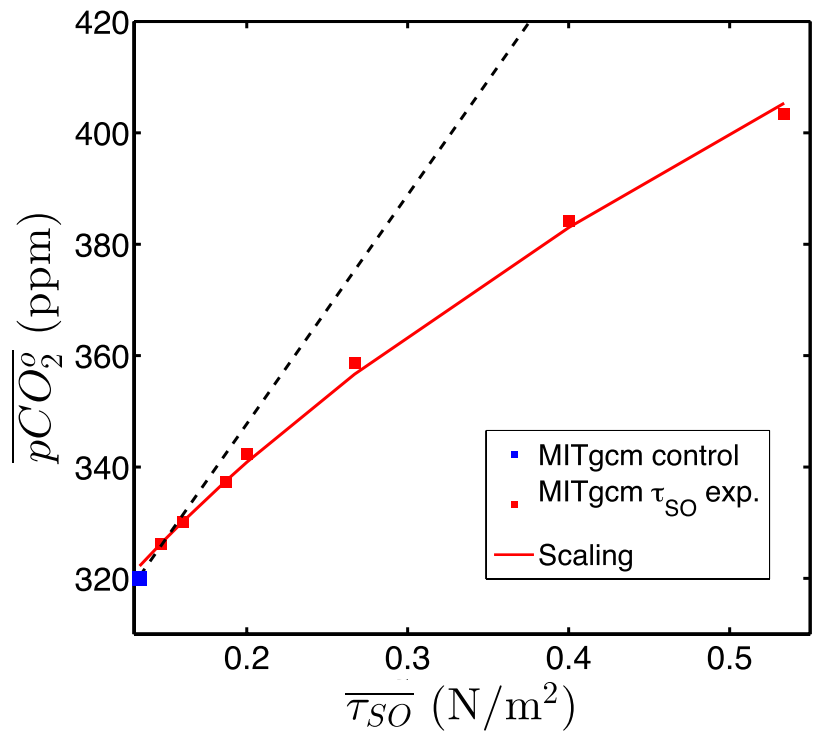

Fig. 5 MITgcm Southern Ocean $p \mathrm{CO}_{2}^{o}$ as a function of averaged channel wind stress, $\overline{\tau_{S O}}$. The blue square denotes the control experiment, and the dashed black line is a linear trend around the control value. The red squares are for the numerical experiments with perturbed wind stress. The red line shows the prediction from Eq. 7 using control state parameters, listed in Table 1

(green curve, a piece-wise linear profile). However the magnitude of the change is slightly increased. When eddies are partially resolved, the magnitude of the $\overline{p \mathrm{CO}_{2}^{o}}$ response to $\overline{\tau_{S O}}$ is seen to be reduced (Munday et al. 2014), without fundamentally changing its character. The set of wind stress perturbation experiments with a $30 \%$ stronger Gent-McWilliams eddy diffusivity parameter described earlier exhibit a similar ${\overline{\tau_{S O}}}^{1 / 2}$ dependence (Fig. 6, cyan curve). The strength of the response is reduced by $10 \%$ in the presence of stronger eddies due to an altered stratification in agreement with other studies (e.g., Mignone et al. 2006), and this reduction is captured by applying the scaling from Eq. 7 .

We address the choice of parametrization of the vertical velocity at the bottom of the mixed layer, $w_{h}$. Other than

Table 1 Area-mean values of the parameters used in the scalings for the MITgcm, HadGEM2-ES and IPSL-CM5 based on each model's control run climatology

\begin{tabular}{llllllllll}
\hline Model & Simulation & $\Delta T\left({ }^{\circ} \mathrm{C}\right)$ & $h(\mathrm{~m})$ & $\Delta_{z} D I C\left(\mathrm{~mol} / \mathrm{m}^{3}\right)$ & $g\left(\mathrm{~m} / \mathrm{s}^{2}\right)$ & $\alpha\left({ }^{\circ} \mathrm{C}^{-1}\right)$ & $\rho_{0}\left(\mathrm{kgm}^{-3}\right)$ & $m_{0}$ & $K\left(\mathrm{~mol} \mathrm{~m}^{-2} \mathrm{~s}^{-1} \mathrm{ppm}^{-1}\right)$ \\
\hline MITgcm & Control & 4.7 & 70 & -0.11 & 9.81 & $2.1 \times 10^{-4}$ & 1026 & 0.5 & $5.4 \times 10^{-9}$ \\
HadGEM2-ES & Control & 2.4 & 80 & -0.13 & 9.81 & $2.1 \times 10^{-4}$ & 1026 & 0.5 & $2 \times 10^{-8}$ \\
IPSL-CM5 & Control & 9.3 & 94 & -0.11 & 9.81 & $2.1 \times 10^{-4}$ & 1026 & 0.5 & $7 \times 10^{-9}$ \\
HadGEM2-ES & $2 \times \mathrm{CO}_{2}$ & 3.1 & 78 & -0.11 & 9.81 & $2.1 \times 10^{-4}$ & 1026 & 0.5 & $2 \times 10^{-8}$ \\
IPSL-CM5 & $2 \times \mathrm{CO}_{2}$ & 7.4 & 96 & -0.12 & 9.81 & $2.1 \times 10^{-4}$ & 1026 & 0.5 & $7 \times 10^{-9}$ \\
\hline
\end{tabular}

Also listed are the values of the same parameters for HadGEM2-ES and IPSL-CM5 as calculated as the mean over the last 10 years of a 140 year long abrupt $2 \times$ atmospheric $\mathrm{CO}_{2}$ experiment 


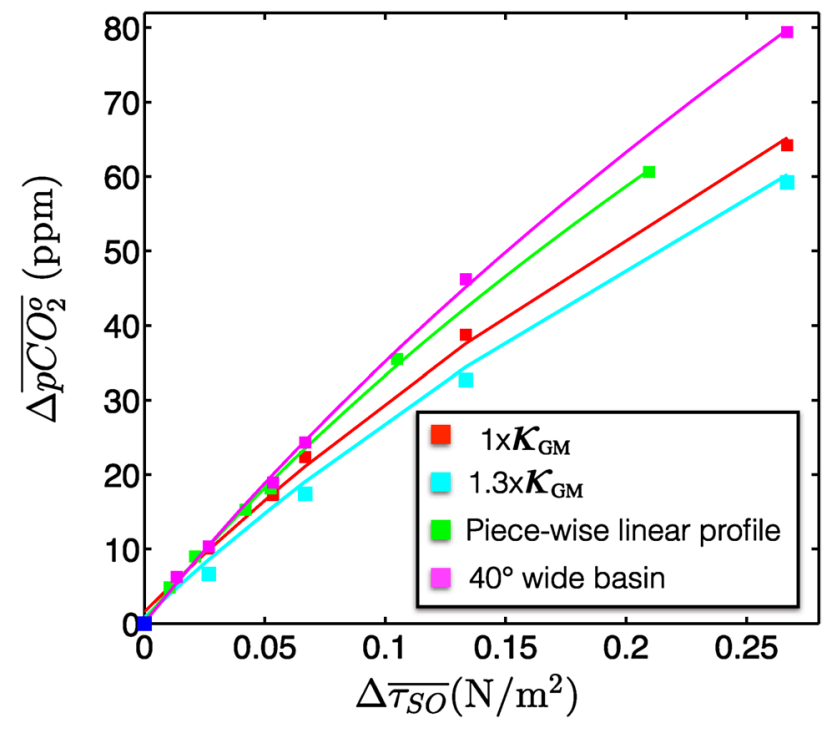

Fig. 6 Response of the MITgcm Southern Ocean $\overline{p \mathrm{CO}_{2}^{o}}$ as a function of a change in Southern Ocean wind stress, $\Delta \overline{\tau_{S O}}$, relative to the control run denoted by the blue square. The colored squares are the perturbed experiments (after 400 years of model run) for the standard scenario as used in Fig. 5 (red), a 30\% stronger GM coefficient (cyan), a piecewise linear wind stress profile between $60^{\circ}$ and $20^{\circ} \mathrm{S}$ (green) and for a model domain $40^{\circ}$ wide (magenta). The matching colored lines are the predictions using the scaling from Eq. 7

using Eq. 3, one could express the large scale vertical velocity as a function of the wind stress divergence. To compare results using these different approaches, the magnitude of $w_{h}$ calculated using the parametrization (red), wind stress divergence (green) and as modelled by MITgcm (black) is shown in Fig. 7. Neither approach gives an exact match for the modelled $w_{h}$ : Eq. 3 overestimates $w_{h}$ as the wind stress increases by $2-40 \%$ (especially at high $\overline{\tau_{S O}}$ ) while the wind stress divergence underestimates the trend in $w_{h}$ by $6-25 \%$. We rule out using a parametrization based on the wind stress divergence, since it leads to larger errors in the $\overline{p \mathrm{CO}_{2}^{o}}$ prediction up to a doubling in $\overline{\tau_{S O}}$ : the divergence gives a $6 \%$ error in $\overline{p \mathrm{CO}_{2}^{o}}$ at $1.2 \times \overline{\tau_{S O}}$ compared to a $1 \%$ error with the square-root parametrization.

Equations 7 and 9 are useful for disentangling the effects of Southern Ocean wind stress from other forcings on ocean and atmospheric $p \mathrm{CO}_{2}$ in complex climate models. Figure 8 shows the response of atmospheric $p \mathrm{CO}_{2}^{a}$ to increasing $\overline{\tau_{S O}}$ in MITgcm (black squares) and the predicted $p \mathrm{CO}_{2}^{a}$ using Eq. 9 for the MITgem (black curve), as well as HadGEM2-ES (red) and IPSL-CM5 from CMIP5 (green). HadGEM2-ES and IPSL-CM5 are chosen since they are not biased towards a strong or weak climate response. Results are plotted as a difference to the control state of each model. Values of $\Delta_{z} D I C, h$ and $\Delta_{z} T$ vary by as much as $400 \%$ (see Table 1 ) between models, however the overall response in atmospheric $p \mathrm{CO}_{2}^{a}$ is of the same order of magnitude.

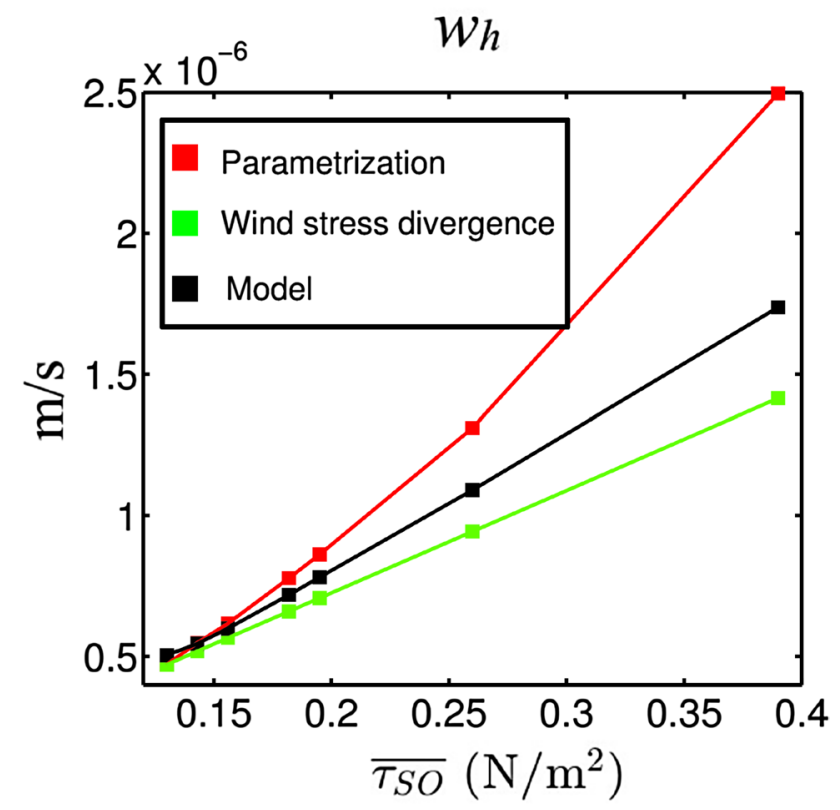

Fig. 7 Vertical velocity at the bottom of the mixed layer, $w_{h}$, as a function of $\overline{\tau_{S O}}$ as calculated using the parametrization (Eq. 3, red), wind stress divergence (green) and as modelled by MITgcm (black)

The MITgcm prediction follows the model response, with a maximum error in $p \mathrm{CO}_{2}^{a}$ of $5 \%$ for a $\Delta \overline{\tau_{S O}}$ of $0.13 \mathrm{~N} / \mathrm{m}^{2}$ (a doubling of $\overline{\tau_{S O}}$ ). In these experiments, the change in the preformed carbon reservoir is larger than the

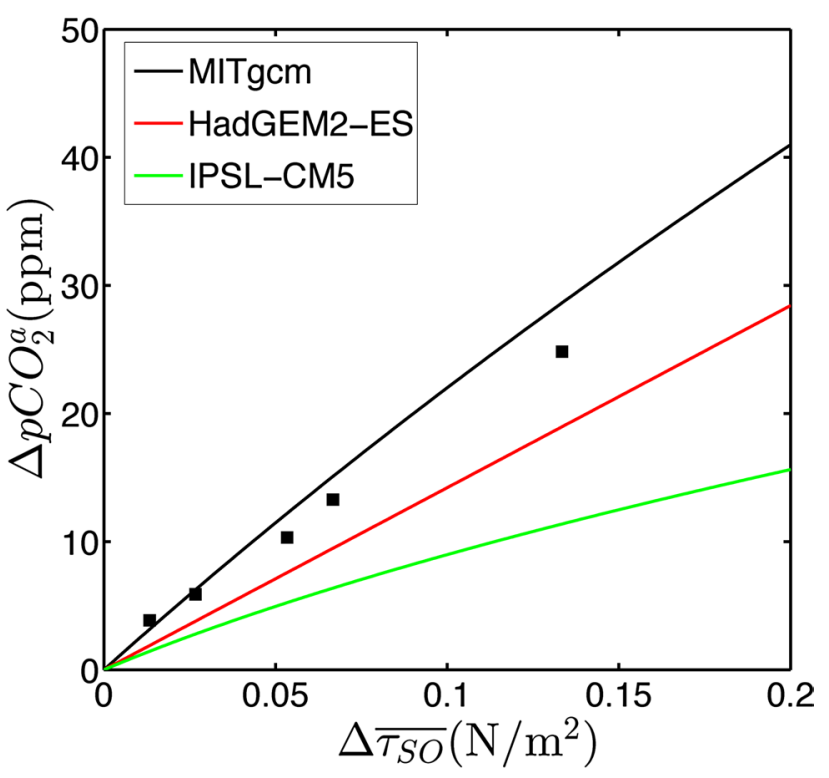

Fig. 8 Change in atmospheric $p \mathrm{CO}_{2}$ as a function of a change in Southern Ocean wind stress, $\Delta \overline{\tau_{S O}}$, relative to a control run for MITgcm (black squares). The black, red and green lines show the change in predicted atmospheric $p \mathrm{CO}_{2}$, using Eq. 9, in the MITgcm, HadGEM2-ES and IPSL-CM5, respectively. The parameters used in Eq. 9 are given in Table 1 for each model 
change in the regenerated carbon reservoir across all wind strengths. The CMIP5 models considered in this paper predict a $~ 30 \%$ increase in Southern Hemisphere wind stress after 140 years of an abrupt $2 \times \mathrm{CO}_{2}$ scenario, causing a predicted increase in equilibrium atmospheric $\mathrm{pCO}_{2}$ due to Southern Ocean wind stress of 4-9 ppm, according to our scaling (Eq. 9), should winds stabilise at this level. Swart and Fyfe (2012) point out that CMIP5 models strongly underestimate $\overline{\tau_{S O}}$ in historical simulations. An equilibrium response in $p \mathrm{CO}_{2}^{a}$ of $4-9 \mathrm{ppm}$ is therefore a lower estimate.

Other factors might influence atmospheric $p \mathrm{CO}_{2}$ as mentioned above, such as stratification, overturning strength and biological pump strength (e.g., Mignone et al. 2006; Marinov and Gnanadesikan 2011; Munday et al. 2014; Lauderdale et al. 2017). For example, Bronselaer et al. (2016) shows that Southern Ocean winds can induce changes in the North Atlantic air-sea carbon flux via oceanic teleconnections and the response of the biology outside of the Southern Ocean. In such cases, the air-sea fluxes outside the Southern Ocean can have an important influence on atmospheric $p \mathrm{CO}_{2}$ (i.e., meaning increasing $G_{2}$ in Eq. 9). To further test the robustness of our prediction due to the influence of biological production and non-local air-sea fluxes, we perform a $2 \times \overline{\tau_{S O}}$ wind perturbation experiment in which the biology is perturbed, by halving the nutrient limitation coefficient [as in Bronselaer et al. (2016)].

The experiment leads to an increase in biological productivity throughout the global ocean, in particular the tropics and mid-latitudes, likely driven by an increase in the Ekman transport of nutrients out of the Southern Ocean (Williams and Follows 1998). The Southern Ocean $\overline{p C O_{2}^{o}}$ increase under the $2 \times \overline{\tau_{S O}}$ perturbation is $18 \%$ weaker in the perturbed-biology experiment than in the original experiment. Outside the Southern Ocean, the $p \mathrm{CO}_{2}^{o}$ increases more when the biology is perturbed as expected from Bronselaer et al. (2016). Applying Eq. 7 to our simulation captures the muted response of the Southern Ocean $\overline{p \mathrm{CO}_{2}^{o}}$, due to a reduction in $\Delta_{z}$ DIC. Similarly, the $p \mathrm{CO}_{2}^{a}$ anomaly is reduced by $20 \%$ when biology is perturbed. The error between the modelled and predicted $p \mathrm{CO}_{2}^{a}$ using Eq. 9 in the biologically perturbed wind stress experiment is similar to that of the standard experiments. The changes in the preformed and regenerated carbon reservoirs are $30 \%$ larger in the biologically perturbed experiment compared to the standard $2 \times \overline{\tau_{S O}}$ experiment, yet it is still the change in the pre-formed reservoir that dominates (not shown). Despite an increase in tropical and mid-latitude $p \mathrm{CO}_{2}^{o}$ in the biologically-perturbed $2 \times \overline{\tau_{S O}}$ experiment, the $p \mathrm{CO}_{2}^{a}$ anomaly is reduced, dictated by the muted response in the Southern Ocean but is still captured with our scalings.

\section{Sensitivity to surface warming and anthropogenic emissions}

\subsection{Warming and stratification}

A rise in atmospheric $\mathrm{CO}_{2}$ levels, in addition to strengthening the Southern Ocean westerly winds, leads to an increase in atmospheric and surface ocean temperature and increased ocean stratification. Equation 7 indicates that changes in stratification, encapsulated in $\Delta_{z} T$ and $h$, can alter the response to wind stress of Southern Ocean $p C O_{2}^{o}$ and air-sea carbon fluxes. Figure 9 shows control mean air-sea carbon flux for HadGEM2-ES and IPSLCM5 (panels a and c, respectively) and the change in stratification $\Delta_{z} T$ at the end of an abrupt $2 \times \mathrm{CO}_{2}$ experiment relative to the control run for HadGEM2-ES (panel b) and IPSL-CM5 (panel d). An increase of several degrees in $\Delta_{z} T$ across most of the areas of carbon outgassing is evident in HadGEM2-ES. In IPSL-CM5 however, changes in ocean dynamics cause a reduction in $\Delta_{z} T$ leading to a less stratified ocean over most areas of carbon outgassing.

To explore the role of changes in stratification, we run an experiment using the MITgcm idealized set-up whereby the temperature restoring profile shown in Fig. 1c is increased by $30 \%$ across the domain. The model reaches a new equilibrium with a mean increase in $\Delta_{z} T$ of $1.5^{\circ} \mathrm{C}$ over the Southern Ocean, as well as an elevated mean state $\overline{p \mathrm{CO}_{2}^{o}}$. We then perform a sensitivity study to wind stress as described in Sect. 3. The response of the warmer mean state compared to the original experiments is shown in Fig. 10a. Due to the increase in the vertical temperature gradient, the sensitivity of $\overline{p \mathrm{CO}_{2}^{o}}$ to $\overline{\tau_{S O}}$ is weakened; this is captured by the scaling with a maximum error in $\overline{p \mathrm{CO}_{2}^{o}}$ of 3\%. For the CMIP5 models shown in Fig. 9, we calculate the sensitivity of $\overline{p \mathrm{CO}_{2}^{o}}$ to wind stress using $\Delta_{z} D I C$, $h$ and $\Delta_{z} T$ from the control state and also at the end of the $2 \times \mathrm{CO}_{2}$ experiments. Figure $10 \mathrm{~b}$ compares the $p \mathrm{CO}_{2}^{a}$ response using both the control run and the $2 \times \mathrm{CO}_{2}$ sensitivities. For HadGEM2-ES, the sensitivity is reduced by $35 \%$ in the warm scenario whereas for IPSL-CM5, the reduction in vertical temperature gradient increases the sensitivity by $36 \%$. Therefore an increased stratification acts as a negative feedback on the atmospheric $\mathrm{pCO}_{2}$.

\subsection{Anthropogenic carbon}

The Southern Ocean is a net sink of carbon since current anthropogenic atmospheric $\mathrm{CO}_{2}$ levels are high enough to drive a flux of carbon into the Southern Ocean. By altering the background Southern Ocean $p \mathrm{CO}_{2}^{o}$, the anthropogenic sink could potentially be reduced or reversed. To 

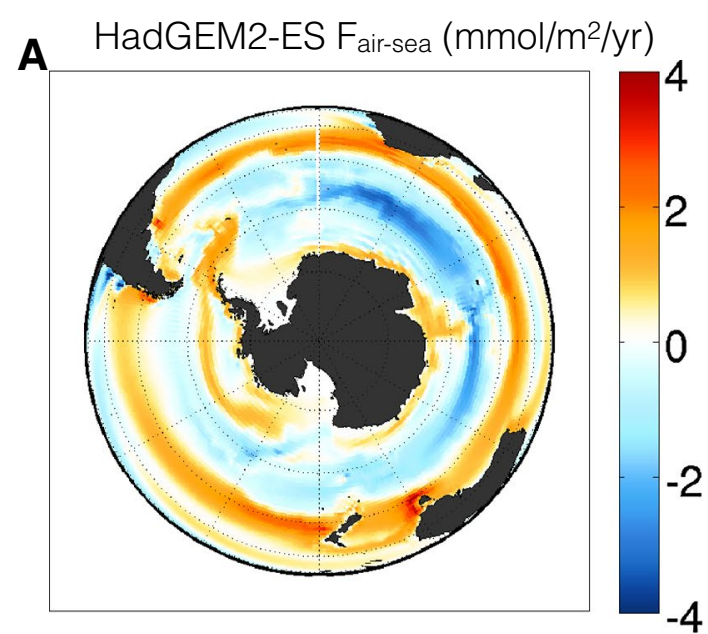

C IPSL-CM5 $\mathrm{F}_{\text {air-sea }}\left(\mathrm{mmol} / \mathrm{m}^{2} / \mathrm{yr}\right)$
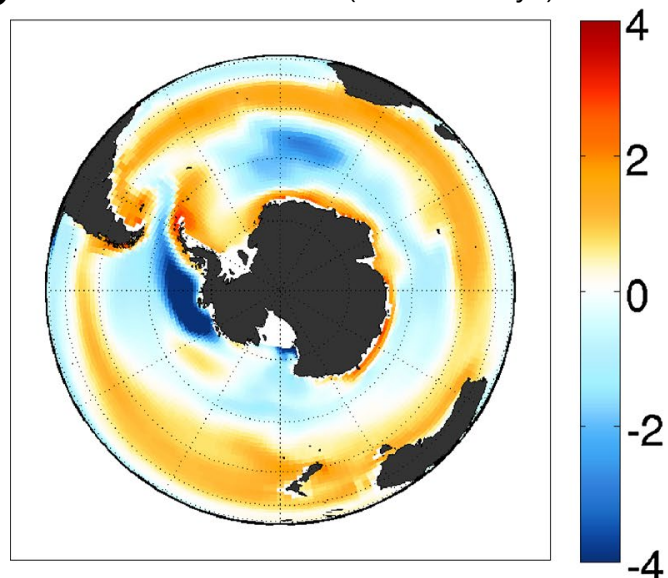

Fig. 9 Southern Ocean air-sea carbon flux in $\mathrm{mol} / \mathrm{m}^{2} /$ year from control runs of a HadGEM2-ES and c IPSL-CM5; negative values indicates outgassing from the ocean to atmosphere. Change in verti-

investigate the effects of Southern Ocean wind stress on the anthropogenic carbon flux, we run a set of MITgcm experiments whereby we increase $\overline{\tau_{S O}}$ as before. In addition, we introduce an anthropogenic $\mathrm{CO}_{2}$ pulse by increasing the initial control $p \mathrm{CO}_{2}^{a}$ of 300 by $260 \mathrm{ppm}$ (to give $560 \mathrm{ppm}$, equivalent to a CMIP5 $2 \times \mathrm{CO}_{2}$ scenario). We then monitor the transient adjustment of the anthropogenic carbon as the ocean responds to the wind stress anomaly.

Results show that wind stress changes reduce the annualmean carbon flux into the ocean by $0.04 \mathrm{~mol} / \mathrm{m}^{2} /$ year for every $0.012 \mathrm{~N} / \mathrm{m}^{2}$ increase in $\overline{\tau_{S O}}$. Such a change accumulates over time. The net sink of carbon, set by the integrated flux over time, should exhibit a $\overline{\tau_{S O}} 1 / 2$-relationship. The cumulative uptake between $60^{\circ}$ and $20^{\circ} \mathrm{S}$ (assuming no dynamical changes apart from the Southern Ocean), shown in Fig. 10c, d, indeed scales as ${\overline{\tau_{S O}}}^{1 / 2}$ as predicted, on decadal to centennial timescales. After several centuries, for Southern Ocean wind stress perturbations larger than $70 \%$,
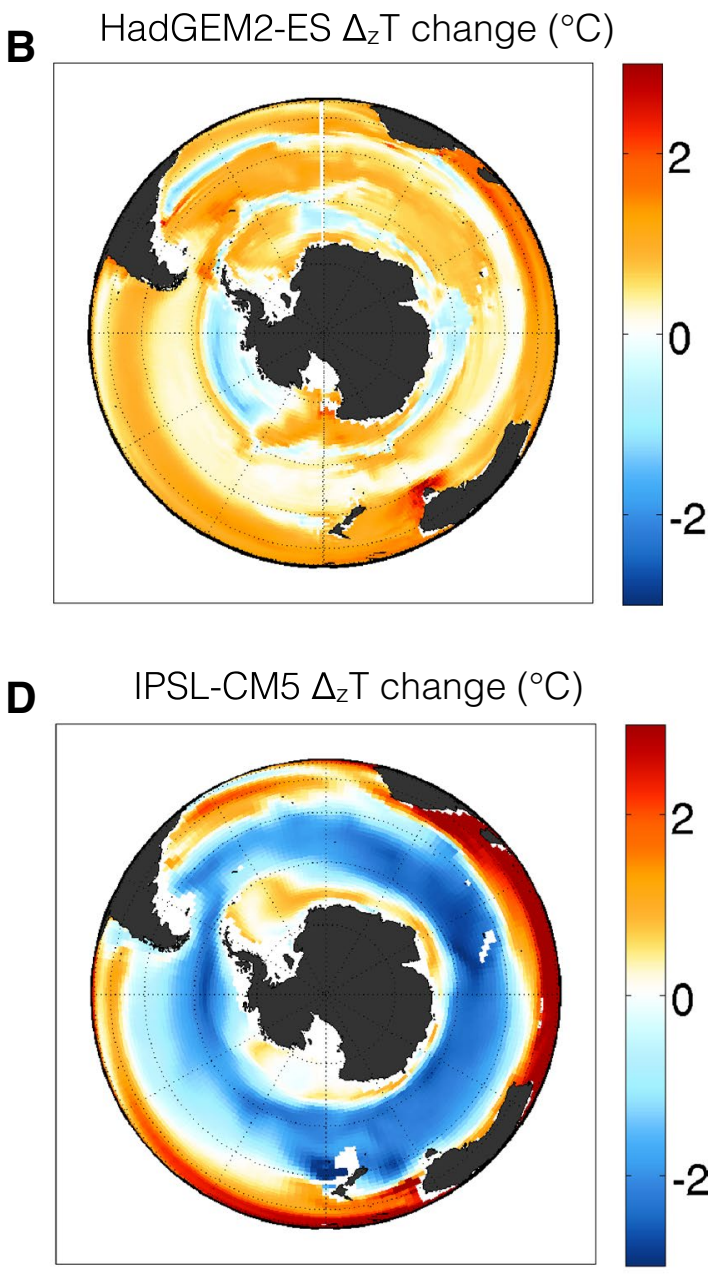

cal temperature difference $\Delta_{z} T$, in ${ }^{\circ} \mathrm{C}$, between the mixed layer and $1000 \mathrm{~m}$ depth in b HadGEM2-ES and d IPSL-CM5 in the last 10 years of a $2 \times \mathrm{CO}_{2}$ relative to the control run

the sign of the flux flips to act as a source for carbon-degassing carbon from the Southern Ocean into the atmosphere. For wind stress values up to $0.22 \mathrm{~N} / \mathrm{m}^{2}$, the Southern Ocean continues to act as a reduced sink (Fig. 10d). Changes in the modern day Southern Ocean carbon sink may therefore accumulate and become more apparent with time.

\section{Conclusions}

In this work, we quantify the Southern Ocean climate-carbon feedback through examination of physical processes influencing ocean $p \mathrm{CO}_{2}^{o}$ under increased wind stress. A mixed layer carbon budget is used to derive an equilibrium equation relating Southern Ocean wind stress to the area-mean partial pressure of carbon in the Southern Ocean, $\overline{p \mathrm{CO}_{2}^{o}}$. Southern Ocean $p \mathrm{CO}_{2}^{o}$ is shown to vary as the square root of the mean wind stress, while its sensitivity depends on the local 

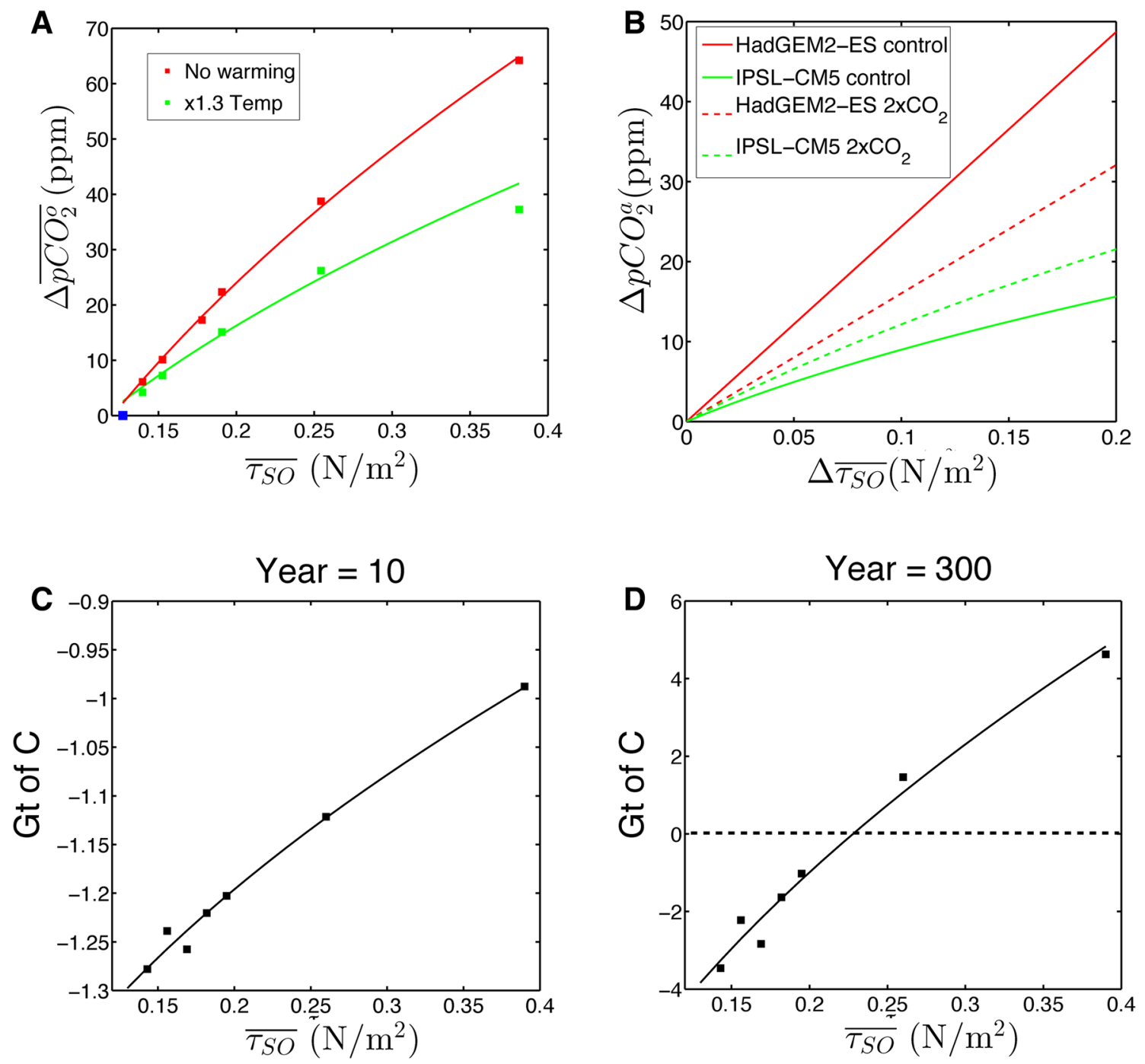

Fig. 10 a Change in MITgcm Southern Ocean $p \mathrm{CO}_{2}^{o}$ as a function of channel wind stress relative to a control state (red, the same as in Fig. 5a) and elevated sea surface temperature control state (green), b Predicted change in atmospheric $p \mathrm{CO}_{2}$ in HadGEM2-ES (red) and

DIC concentration, mixed layer depth and stratification. The relationship is verified using wind stress perturbation experiments performed with an idealised coarse-resolution MITgcm model set-up. The square root dependency of $\overline{p \mathrm{CO}_{2}^{o}}$ on $\overline{\tau_{S O}}$ highlights the importance of wind-induced entrainment at the bottom of the mixed layer over lateral Ekman transport. Using the expression for $\overline{p \mathrm{CO}_{2}^{o}}$, we can predict the variation of atmospheric $p \mathrm{CO}_{2}$ using only a few parameters: mixed layer carbon content, mixed layer depth and the vertical temperature gradient.

We use MITgcm experiments to test the response of Southern Ocean $p \mathrm{CO}_{2}^{o}$ to climate change scenarios. Increased stratification through surface warming is shown to reduce the sensitivity of $\overline{p \mathrm{CO}_{2}^{o}}$ to $\overline{\tau_{S O}}$. When applying the projections to the CMIP5 archive, increased
IPSL-CM5 (green) using parameters from the control run (solid lines) and from the end of a $2 \times \mathrm{CO}_{2}$ experiment (dashed lines). c, $\mathbf{d}$ Cumulative Southern Ocean sea-air carbon flux in MITgcm at year 10 (c) and year $300(\mathbf{d})$ after a $260 \mathrm{ppm}$ anthropogenic $\mathrm{CO}_{2}$ pulse emission

(decreased) vertical temperature gradients induced under a $2 \times \mathrm{CO}_{2}$ forcing reduce (increase) the sensitivity of $p \mathrm{CO}_{2}^{a}$ to $\overline{\tau_{S O}}$. Experiments with both wind stress and anthropogenic carbon perturbations show that the cumulative Southern Ocean carbon uptake also varies as the square root of the area-mean wind stress. The annual carbon flux into the Southern Ocean is reduced by $0.04 \mathrm{~mol} / \mathrm{m}^{2} /$ year for every $0.012 \mathrm{~N} / \mathrm{m}^{2}$ increase in mean wind stress between $60^{\circ}$ and $40^{\circ} \mathrm{S}$. These changes are an order of magnitude smaller than the decadal variability in the carbon flux (Landschutzer et al. 2015). However, this variability is on top of the long term trend. Using the measured trends in Southern Ocean wind stress from Swart and Fyfe (2012), Landschutzer et al. (2015)'s results suggest that if Southern Ocean winds and atmospheric $p \mathrm{CO}_{2}$ were to stabilize, 
the long-term air-sea flux of carbon would be reduced by about $20 \%$.

Our work complements other studies on the Southern Ocean air-sea fluxes of carbon. Ito and Follows (2013) show that DIC is upwelled into the Southern Ocean mixed layer where it is exposed to the atmosphere, leading to outgassing. However, the authors point out that the air-sea equilibration is inefficient leading to only a partial release of $\mathrm{CO}_{2}$ to the atmosphere. Ito et al. (2015) demonstrate that under climate change, elevated westerly winds not only increase outgassing of natural carbon, but also increase the ocean uptake of anthropogenic carbon. Munday et al. (2014) show that changes in the carbon inventories lead to changes in atmospheric $p \mathrm{CO}_{2}$ under increased wind stress. Lauderdale (2010) and Lauderdale et al. (2013, 2017) show that there are substantially changes in the Southern Ocean air-sea flux of carbon on a range a timescales under different wind stress forcing.

In the models of Mignone et al. (2006) and Russell et al. (2006) the uptake of anthropogenic carbon under increasing winds is enhanced. They explain this via an argument based on the deepening of the pycnocline under increased wind stress. Essentially, increased wind stress leads to increased Ekman transport of water out of the Southern Ocean and therefore a thickening of the warm near surface layer to the north (the pycnocline). The anthropogenic carbon then fills this larger "box" and carbon uptake is enhanced, with respect to a model in which the pycnocline does not deepen, or deepens to a lesser extent. This appears to contrast with our results, which show a comparatively small increased uptake of anthropogenic carbon when wind stress is increased and ultimately a switch to degassing of carbon for high winds and long timescales (Sect. 4.2). These apparently contradictory results can be reconciled by considering differences in model and experimental design.

One caveat is that the MITgcm model set-up uses a parametrization to represent eddy transports. However, most CMIP5 models use the same parametrization, so our results and scaling are appropriate for analysing wind stress feedbacks in CMIP5. Nonetheless, studies show that resolved eddies reduce the Southern Ocean carbon response to wind stress perturbations, by means of the effect of eddies on the residual circulation (Hallberg and Gnanadesikan 2006) and their role in setting the stratification of the ocean (Marshall et al. 2002; Henning and Vallis 2004), rather than direct carbon transport by the eddy-induced velocity. While further work is needed to determine the impact of eddies on the feedback, additional experiments with a stronger eddy diffusivity parameter show a reduction in the sensitivity of $p \mathrm{CO}_{2}^{a}$ to $\overline{\tau_{S O}}$ by affecting the background stratification, an effect that our proposed scaling captures well.
Acknowledgements BB was supported by a NERC CASE studentship with the Met Office. Further support from NERC was provided to LZ and DRM. This work made use of the facilities of HECToR and Archer. We acknowledge the World Climate Research Programme's Working Group on Coupled Modelling, which is responsible for CMIP archive and the MITgcm team for making their code publicly available. We thank the reviewers for their useful comments which helped improve the manuscript.

Open Access This article is distributed under the terms of the Creative Commons Attribution 4.0 International License (http://creativeco mmons.org/licenses/by/4.0/), which permits unrestricted use, distribution, and reproduction in any medium, provided you give appropriate credit to the original author(s) and the source, provide a link to the Creative Commons license, and indicate if changes were made.

\section{Appendix: Atmospheric $p \mathrm{CO}_{2}$ feedback equation}

Equation 7 for $\overline{p \mathrm{CO}_{2}^{o}}\left(\overline{\tau_{S O}}\right)$ can be used to calculate atmospheric $p \mathrm{CO}_{2}, p \mathrm{CO}_{2}^{a}$. To obtain an equation for $p \mathrm{CO}_{2}^{a}$, we integrate the air-sea flux equation over the entire ocean basin to give:

$p \mathrm{CO}_{2}^{a}=P_{S O} \overline{p \mathrm{CO}_{2}^{o}}\left(\overline{\tau_{S O}}\right)+P_{E} \overline{p \mathrm{CO}_{2 E}^{o}}$.

The area fraction of the Southern Ocean relative to the global ocean, weighted by the local wind stress is given by $P_{S O}=A_{S O} K \overline{\tau_{S O}}\left(A_{S O} K \overline{\tau_{S O}}+A_{E} K \overline{\tau_{E}}\right)^{-1}$, where $A$ is the area and the subscript " $S O$ " and " $E$ " indicate the Southern Ocean and rest of the global ocean, respectively. Substituting for $\overline{p \mathrm{CO}_{2}^{o}}\left(\overline{\tau_{S O}}\right)$ using Eq. 7 and solving for $p \mathrm{CO}_{2}^{a}$ gives:

$$
\begin{aligned}
p \mathrm{CO}_{2}^{a}= & {\left[\frac{P_{S O}}{1-P_{S O}}\right] \overline{\frac{-\Delta_{z} D I C}{h} \frac{2 m_{0}}{K \alpha g \Delta_{z} T \rho_{0}^{3 / 2}}} \bar{\tau}_{S O}^{1 / 2} } \\
& +G_{2}\left(v, Q, F_{b i o}, p \mathrm{CO}_{2 E}^{o}\right)
\end{aligned}
$$

where the term $G_{2}$ is given by:

$$
\begin{gathered}
G_{2}\left(v, Q, F_{b i o}, p \mathrm{CO}_{2 E}^{o}\right)=\frac{P_{S O}}{1-P_{S O}} \overline{\left(\frac{-\Delta_{z} D I C}{K}\right) \frac{Q}{\Delta_{z} T \rho_{0} C_{p} \tau_{S O}}} \\
-\frac{P_{S O}}{1-P_{S O}} \overline{\left(\frac{\Delta_{z} D I C}{K h}\right) \frac{\left(1-e_{G M}\right)}{\rho_{0} f} \frac{\partial h}{\partial y}} \\
+\frac{P_{S O}}{1-P_{S O}} \overline{\frac{\left[F_{b i o}\right]_{h}}{K \tau_{S O}}}+\frac{P_{E}}{1-P_{S O}} p \mathrm{CO}_{2 E}^{o} .
\end{gathered}
$$

\section{References}

Bracegirdle TJ, Shuckburgh E, Sallee J-B, Wang Z, Meijers AJS, Bruneau N, Phillips T, Wilcox LJ (2013) Assessment of surface winds over the Atlantic, Indian, and Pacific Ocean sectors 
of the Southern Ocean in CMIP5 models: historical bias, forcing response, and state dependence. J Geophys Res Atmos 118(2):547-562

Broecker W (1974) NO A conservative water-mass tracer. Earth Planet Sci Lett 23(1):100-107

Bronselaer B (2016) Climate-carbon feedback of the high latitude ocean. Ph.d. Thesis, University of Oxford, Oxford, UK

Bronselaer B, Zanna L, Munday DR, Lowe J (2016) The influence of Southern Ocean winds on the North Atlantic carbon sink. Glob Biogeochem Cycles 30(6):844-858

Davis R, Deszoeke R, Niler P (1981) Variability in the upper ocean during mile. 2. Modeling the mixed layer response. Deep Sea Res Part A Oceanogr Res Pap 28(12):1453-1475

Fay AR, McKinley GA (2013) Global trends in surface ocean $p \mathrm{CO}_{2}$ from in situ data. Glob Biogeochem Cycles 27(2):541-557

Follows M, Ito T, Dutkiewicz S (2006) On the solution of the carbonate chemistry system in ocean biogeochemistry models. Ocean Model 12(3-4):290-301

Follows MJ, Williams RG (2004) Mechanisms controlling the air-sea flux of $\mathrm{CO}_{2}$ in the north atlantic. In: The Ocean Carbon Cycle and Climate, Springer, Dordrecht, pp 217-249

Gent P, McWilliams J (1990) Isopycnal mixing in ocean circulation models. J Phys Oceanogr 20(1):150-155

Goodwin P, Follows MJ, Williams RG (2008) Analytical relationships between atmospheric carbon dioxide, carbon emissions, and ocean processes. Glob Biogeochem Cycles 22(3). http://dx.doi. org/10.1029/2008GB003184

Goodwin P, Williams RG, Follows M, Dutkiewicz S (2007) Oceanatmosphere partitioning of anthropogenic carbon dioxide on centennial timescales. Glob Biogeochem Cycles 21(1). http://dx.doi. org/10.1029/2006GB002810

Gruber N (1998) Anthropogenic $\mathrm{CO}_{2}$ in the Atlantic Ocean. Glob Biogeochem Cycles 12(1):165-191

Hallberg R, Gnanadesikan A (2006) The role of eddies in determining the structure and response of the wind-driven southern hemisphere overturning: results from the modeling eddies in the Southern Ocean (MESO) project. J Phys Oceanogr 36(12):2232-2252

Henning C, Vallis G (2004) The effects of mesoscale eddies on the main subtropical thermocline. J Phys Oceanogr 34(11):2428-2443

Ito T, Bracco A, Deutsch C, Frenzel H, Long M, Takano Y (2015) Sustained growth of the Southern Ocean carbon storage in a warming climate. Geophys Res Lett 42(11):4516-4522

Ito T, Follows M (2003) Upper ocean control on the solubility pump of $\mathrm{CO}_{2}$. J Mar Res 61(4):465-489

Ito T, Follows M (2005) Preformed phosphate, soft tissue pump and atmospheric $\mathrm{CO}_{2}$. J Mar Res 63(4):813-839

Ito T, Follows MJ (2013) Air-sea disequilibrium of carbon dioxide enhances the biological carbon sequestration in the Southern Ocean. Glob Biogeochem Cycles 27(4):1129-1138

Ito T, Marshall J, Follows M (2004) What controls the uptake of transient tracers in the Southern Ocean? Glob Biogeochem Cycles 18(2). http://dx.doi.org/10.1029/2003GB002103

Khatiwala S, Primeau F, Hall T (2009) Reconstruction of the history of anthropogenic $\mathrm{CO}_{2}$ concentrations in the ocean. Nature 462(7271):346-349

Landschutzer P, Gruber N, Haumann A, Rodenbeck C, Bakker DCE, van Heuven S, Hoppema M, Metzl N, Sweeney C, Takahashi T, Tilbrook B, Wanninkhof R (2015) The reinvigoration of the Southern Ocean carbon sink. Science 349(6253):1221-1224

Lauderdale $\mathbf{J}$ (2010) On the role of the southern ocean in the global carbon cycle and atmospheric $\mathrm{CO}_{2}$ change. Doctoral dissertation, University of Southampton, Southampton

Lauderdale JM, Dutkiewicz S, Williams RG, Follows MJ (2016) Quantifying the drivers of ocean-atmosphere $\mathrm{CO}_{2}$ fluxes. Glob Biogeochem Cycles 30(7):983-999
Lauderdale JM, Garabato ACN, Oliver KIC, Follows MJ, Williams RG (2013) Wind-driven changes in Southern Ocean residual circulation, ocean carbon reservoirs and atmospheric $\mathrm{CO}_{2}$. Clim Dyn 41(7-8):2145-2164

Lauderdale JM, Williams RG, Munday DR, Marshall DP (2017) The impact of southern ocean residual upwelling on atmospheric $\mathrm{co}_{2}$ on centennial and millennial timescales. Clim Dyn 48(5):16111631. https://doi.org/10.1007/s00382-016-3163-y

Le Quere C, Roedenbeck C, Buitenhuis ET, Conway TJ, Langenfelds R, Gomez A, Labuschagne C, Ramonet M, Nakazawa T, Metzl N, Gillett N, Heimann M (2007) Saturation of the Southern Ocean $\mathrm{CO}_{2}$ sink due to recent climate change. Science 316(5832): 1735-1738

Lenton A, Tilbrook B, Law RM, Bakker D, Doney SC, Gruber N, Ishii M, Hoppema M, Lovenduski NS, Matear RJ, McNeil BI, Metzl N, Fletcher SEM, Monteiro PMS, Roedenbeck C, Sweeney C, Takahashi T (2013) Sea-air $\mathrm{CO}_{2}$ fluxes in the Southern Ocean for the period 1990-2009. Biogeosciences 10(6):4037-4054

Levy M, Bopp L, Karleskind P, Resplandy L, Ethe C, Pinsard F (2013) Physical pathways for carbon transfers between the surface mixed layer and the ocean interior. Glob Biogeochem Cycles 27(4):1001-1012

Lovenduski NS, Ito T (2009) The future evolution of the Southern Ocean $\mathrm{CO}_{2}$ sink. J Mar Res 67(5):597-617

Majkut JD, Sarmiento JL, Rodgers KB (2014) A growing oceanic carbon uptake: results from an inversion study of surface $p \mathrm{CO}_{2}$ data. Glob Biogeochem Cycles 28(4):335-351

Marinov I, Gnanadesikan A (2011) Changes in ocean circulation and carbon storage are decoupled from air-sea $\mathrm{CO}_{2}$ fluxes. Biogeosciences 8(2):505-513

Marinov I, Follows M, Gnanadesikan A, Sarmiento JL, Slater RD (2008a) How does ocean biology affect atmospheric $p \mathrm{CO}_{2}$ ? Theory and models. J Geophys Res Oceans 113(C7). http://dx.doi. org/10.1029/2007JC004598

Marinov I, Gnanadesikan A, Sarmiento JL, Toggweiler JR, Follows M, Mignone BK (2008b) Impact of oceanic circulation on biological carbon storage in the ocean and atmospheric $p \mathrm{CO}_{2}$. Glob Biogeochem Cycles 22(3). http://dx.doi.org/10.1029/2007GB002958

Marshall J, Adcroft A, Hill C, Perelman L, Heisey C (1997) A finite-volume, incompressible Navier Stokes model for studies of the ocean on parallel computers. J Geophys Res Oceans 102(C3):5753-5766

Marshall J, Jones H, Karsten R, Wardle R (2002) Can eddies set ocean stratification? J Phys Oceanogr 32(1):26-38

Marshall J, Radko T (2003) Residual-mean solutions for the Antarctic Circumpolar Current and its associated overturning circulation. J Phys Oceanogr 33(11):2341-2354

McKinley GA, Pilcher DJ, Fay AR, Lindsay K, Long MC, Lovenduski NS (2016) Timescales for detection of trends in the ocean carbon sink. Nature 530(7591):469+

Mignone BK, Gnanadesikan A, Sarmiento JL, Slater RD (2006) Central role of southern hemisphere winds and eddies in modulating the oceanic uptake of anthropogenic carbon. Geophys Res Lett. https://doi.org/10.1029/2005GL024464. (101604)

Munday DR, Johnson HL, Marshall DP (2013) Eddy saturation of equilibrated circumpolar currents. J Phys Oceanogr 43(3):507-532

Munday DR, Johnson HL, Marshall DP (2014) Impacts and effects of mesoscale ocean eddies on ocean carbon storage and atmospheric $p \mathrm{CO}_{2}$. Glob Biogeochem Cycles 28(8):877-896

Niiler PP, Kraus EB (1977) One-dimensional models of the upper ocean, modelling and prediction of the upper layers of the Ocean. Pergamon Press, Elmsford

Russell JL, Dixon KW, Gnanadesikan A, Stouffer RJ, Toggweiler JR (2006) The Southern Hemisphere westerlies in a warming world: propping open the door to the deep ocean. J Clim 19(24):6382-6390 
Sarmiento J, Hughes T, Stouffer R, Manabe S (1998) Simulated response of the ocean carbon cycle to anthropogenic climate warming. Nature 393(6682):245-249

Swart NC, Fyfe JC (2012) Observed and simulated changes in the Southern Hemisphere surface westerly wind-stress. Geophys Res Lett 39(16). http://dx.doi.org/10.1029/2012GL052810

Swart NC, Fyfe JC, Saenko OA, Eby M (2014) Wind-driven changes in the ocean carbon sink. Biogeosciences 11(21):6107-6117

Takahashi T, Sutherland SC, Wanninkhof R, Sweeney C, Feely RA, Chipman DW, Hales B, Friederich G, Chavez F, Sabine C, Watson A, Bakker DCE, Schuster U, Metzl N, Yoshikawa-Inoue H, Ishii M, Midorikawa T, Nojiri Y, Koertzinger A, Steinhoff T, Hoppema M, Olafsson J, Arnarson TS, Tilbrook B, Johannessen T, Olsen A, Bellerby R, Wong CS, Delille B, Bates NR, de Baar HJW (2009) Climatological mean and decadal change in surface ocean $p \mathrm{CO}_{2}$, and net sea-air $\mathrm{CO}_{2}$ flux over the global oceans. Deep Sea Res Part Ii Top Stud Oceanogr 56(8-10):554-577

Toggweiler J, Murnane R, Carson S, Gnanadesikan A, Sarmiento J (2003) Representation of the carbon cycle in box models and GCMs-2. Organic pump. Glob Biogeochem Cycles 17(1)

Wanninkhof R (1992) Relationship between wind-speed and gas-exchange over the ocean. J Geophys Res Oceans 97(C5):7373-7382

Williams R, Follows M (1998) The Ekman transfer of nutrients and maintenance of new production over the North Atlantic. Deep Sea Res Part I Oceanogr Res Pap 45(2-3):461-489

Wolfe CL, Cessi P (2010) What sets the strength of the middepth stratification and overturning circulation in eddying ocean models? J Phys Oceanogr 40(7):1520-1538 